Canadian

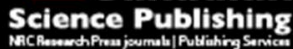

Canadian Geotechnical Journal Revue canadienne de géotechnique

\title{
A framework to assess Newmark-type simplified methods for evaluation of earthquake-induced deformation of embankments
}

\begin{tabular}{|r|l|}
\hline Journal: & Canadian Geotechnical Journal \\
\hline Manuscript ID & cgj-2016-0069.R1 \\
\hline Manuscript Type: & Article \\
\hline Complete List of Authors: & $\begin{array}{l}\text { Esfahani Kan, Mojtaba; University of Wollongong, School of Civil, Mining } \\
\text { and Environmental Engineering } \\
\text { Taiebat, Hossein; University of New South Wales, } \\
\text { Taiebat, Mahdi; University of British Columbia, }\end{array}$ \\
\hline Keyword: & earth/rockfill dam, crest settlement, simplified methods, dynamic analysis \\
\hline \multicolumn{2}{|r}{} \\
\hline
\end{tabular}

\section{SCHOLARONE}

Manuscripts 


\title{
A Framework to Assess Newmark-Type Simplified Methods for Evaluation of Earthquake-Induced Deformation of Embankments
}

\author{
Mojtaba E. Kan ${ }^{1}$, Hossein A. Taiebat ${ }^{2}$, and Mahdi Taiebat ${ }^{3}$
}

\begin{abstract}
The simplified procedures for evaluation of the earthquake induced displacement in earth and rockfill dams are widely used in practice. These methods are simple, inexpensive, and substantially less time consuming as compared to the complicated stress-deformation approaches. They are especially recommended to be used as a screening tool, to identify embankments with marginal factor of safety, assuming that these methods always give conservative estimates of settlements. However recent studies show that application of these methods may not be conservative in some cases, especially when the tuning ratio of a dam is within a certain range. In this paper the fundamental theory behind the simplified methods is critically reviewed. A case in which the results of the simplified methods are reportedly non-conservative is investigated in detail and possible reasons are discussed. The reliability of the simplified methods is examined here based on the existing thresholds proposed in the literature and accounting for the embankment geometry and type, and the seismic activity characterization, and a practical framework is proposed accordingly. The effectiveness of this framework is evaluated in the study of seismic behaviour of a rockfill dam where all simplified procedures failed to predict the order of deformation experienced by the dam under a recent earthquake event.
\end{abstract}

Keywords: earth/rockfill dam, crest settlement, simplified methods, dynamic analysis.

\footnotetext{
${ }^{1}$ Research Fellow, School of Civil, Mining and Environmental Engineering, University of Wollongong, Wollongong, NSW 2522, Australia. Email: mojtaba_kan@uow.edu.au

${ }^{2}$ Senior Lecturer, School of Civil and Environmental Engineering, The University of New South Wales, Sydney, NSW 2052, Australia. Email: h.taiebat@unsw.edu.au

${ }^{3}$ Associate Professor, Department of Civil Engineering, The University of British Columbia, Vancouver, BC, V6T 1Z4, Canada. Email: mtaiebat@civil.ubc.ca (Corresponding author)
} 


\section{Introduction}

Evaluation of the effects of earthquakes on embankments is one of the important issues in design of earth and rockfill dams. Apart from the many cases where earthquakes resulted in liquefaction of materials in embankment and their foundations, there are a large number of cases where earthquakes resulted in sliding and lateral spreading of embankments and settlement of their crests. The deformation patterns of embankment dams under earthquake loading were depicted by Ambraseys (1959) as shown in Figure 1. In the design of a new dam, or in evaluating the earthquake response of an existing dam, it is important to evaluate the settlement of the dam due to earthquake loading. The magnitude of the crest settlement of a dam must be less than the free board of the dam to prevent overtopping and breach.

Different approaches have been proposed for design of earth dams under earthquake loading, ranging from pseudo static stability analysis to simplified dynamic procedures, and to complex stress-deformation analyses. Among these approaches the simplified methods are more popular in practice. However, recent studies show that these methods do not always give a conservative estimate of deformation of dams under earthquake loading (e.g. Rathje and Bray 2000; Nejad et al. 2010; Meehan and Vahedifard 2013).

There are thresholds proposed in the literature for the range of applicability of the simplified methods. The contribution here is converting these thresholds to measurable practical engineering characteristics related to the height and type of the embankment, and the seismic activity of the site. The effectiveness of the proposed framework is evaluated using a recent case history of earthquake effects on a well compacted modern rockfill dam which suffered large deformation. 


\section{Simplified Methods}

Due to complexity of stress-deformation analyses and inadequacy of pseudo-static methods in capturing the real dynamic behaviour of geo-materials, simplified procedures have been widely used in practice to estimate deformation of embankments subjected to earthquake loading. Many of the widely used simplified methods are based on the theoretical framework proposed by Newmark (1965). Several analytical methods have been proposed to simplify or modify the Newmark method (e.g. Sarma 1975; Franklin and Chang 1977; Hynes-Griffin and Franklin 1984; Ambraseys and Menu 1988; Yegian et al. 1991; Bray et al. 1998; WatsonLamprey and Abrahamson 2006; Bray and Travasarou 2007; Jibson 2007; Saygili and Rathje 2008). Here the focus will be on the original Newmark method and the modifications made by Makdisi and Seed (1978) and therefore a brief overview of these methods is presented next.

\section{Rigid Sliding Block Analysis}

Newmark (1965) in the fifth Rankin Lecture proposed a method for evaluation of deformation of embankments due to earthquake loading, which became the basis for further theoretical research in this field. This method is based on the assumption that the behaviour of a potential sliding mass in an embankment is similar to the behaviour of a sliding block on an inclined surface. The block slides only if the earthquake acceleration becomes larger than the yield acceleration of the block. The yield acceleration of a potential sliding block, $k_{y}$, is a horizontal acceleration which results in yielding (or failure) of the block with irrecoverable deformation and can be evaluated from a limit equilibrium analysis. The displacement of a block under earthquake loading can be calculated by double integration of the earthquake acceleration exceeding the yield acceleration of the block. Figure 2 shows the basic concept of the Newmark method. The double integration stops when the velocity of the block and ground coincide. 
In the original Newmark approach it is assumed that the earthquake acceleration applied on different sliding blocks along the height of the dam is equal to the ground acceleration and therefore this method is often called the "rigid sliding block" method. However, Ambraseys and Sarma (1967) studied the effect of eight strong motions with magnitudes ranging from 5.3 to 7.1 and on focal distances of 20 to 60 kilometres and showed that the induced acceleration along the dam height is neither constant nor equal to the ground acceleration.

\section{Flexible Sliding Block Analysis}

Makdisi and Seed (1978) modified and improved the original Newmark method by considering the effect of deformability of embankment dams during earthquake loading. This contribution was based on two-dimensional finite element analyses of some real and hypothetical dams with heights ranging from $30 \mathrm{~m}$ to $60 \mathrm{~m}$, constructed of compacted cohesive or stiff cohesionless materials. The analyses were based on the assumptions that the stiffness of the material is non-linear and is dependent on the level of the cyclic shear strain induced by earthquake loading. The magnitudes of the earthquakes considered range from 6.5 to 8.25 . Based on the results of the finite element analyses two charts were presented through which the acceleration of any sliding block and the horizontal displacement of the block can be determined if the maximum crest acceleration, $\ddot{u}$, and the fundamental period of the embankment, $T_{o}$, are known.

Two different approaches have been derived from the Makdisi and Seed method. The first approach treats the slope as a deformable media and calculates the time history of acceleration of any sliding block along the slope of the dam accordingly. The deformation of the embankment can then be calculated based on the Newmark method. This approach is called "decoupled approach" after Kramer and Smith (1997). The second approach is based on direct 
application of the charts presented by Makdisi and Seed (1978) and here referred to as "direct method".

Despite many evidences which suggest that the deformations of earth and rockfill dams under earthquake loading are mainly in the form of lateral spreading rather than sliding (e.g. Swaisgood 2003), Makdisi and Seed (1978) method is still widely used in practice as an acceptable design tool. Most of the references and guidelines (e.g. ANCOLD 1998) recommend this method to be used as a screening tool before performing any complicated stress-deformation analyses for cases with marginal safety.

\section{Reliability of the Simplified Methods}

The original method proposed by Newmark (1965) and the one modified by Makdisi and Seed (1978) have been perceived to give conservative estimates of deformation of embankment dams under earthquake loading and therefore can be used as screening tools to identify dams with marginal safety. In most of the practical cases, more accurate methods such as stress-deformation analysis are considered, only if the crest settlement obtained by these methods is larger than (or close to) the free board of a dam. However, Makdisi and Seed method was proposed in the 70's when application of computer and numerical methods for engineering purposes was limited. Makdisi and Seed (1978) also highlighted the limitation of their method, stating that "it is a procedure based on few analyses in limited range of applicability and should be improved in future investigations". Nevertheless this method is still widely used in practice. The results of some recent studies also show that the method may not always be conservative:

- Rathje and Bray (1999) investigated application of the simplified methods for evaluation of landfill deformations caused by earthquakes and concluded that the results of the sliding block method are not always conservative. They used an 
analytical formulation for generalized distributed mass and a linear elastic coupled model with a mode shape appropriate for a one dimensional soil column. This model was analysed under 19 records of ground motion as well as under a sinusoidal acceleration. It was shown that for high values of $k_{y} / k_{\max }$ (ratio of the yield acceleration to the maximum induced acceleration) the rigid block or the decoupled method provide less conservative estimates of displacement. Also it was shown that for cases with a high tuning ratio, $T_{0} / T_{m}$ (ratio of the fundamental period of a dam to the mean period of earthquake) the displacements are generally underestimated if the decoupled method is used. In particular for these cases, the displacement obtained by the decoupled method can be significantly smaller than that of the coupled method. Rathje and Bray (1999) also concluded that the rigid sliding block method is generally non-conservative when the frequency content of the input motion is close to the fundamental frequency of the embankment $\left(0.2<T_{o} / T_{m}<2\right.$ to 3$)$.

- Rathje and Bray (2000) performed a series of coupled non-linear stick-slip analyses with a dynamic response program that incorporates a lumped mass in a system with multiple degrees of freedom. They used 24 earthquake motions and showed that the decoupled method is significantly conservative for $T_{0} / T_{m}<1$ while it may be non-conservative for $T_{0} / T_{m}>1$, depending on $k_{y} / k_{\max }$. They also concluded that a rigid block analysis can be either significantly non-conservative or very conservative.

- Wartman et al. (2003) studied the behaviour of a rigid block system and a system of flexible column of soil resting on an inclined surface, both subjected to simulated earthquake excitation on a shaking table. By comparing the displacements of the two systems, it was shown that the rigid sliding block method is generally nonconservative for tuning ratios between 0.2 and 1.3 . 
In summary, Rathje and Bray $(1999,2000)$ and Wartman et al. (2003) have found that the tuning ratio has an important effect on the deformation of earth structures due to earthquake loading and the simplified procedures may be non-conservative within a certain range of tuning ratios. A summary of these investigations is presented in Table 1. It can be seen that although there is no well-defined boundary where the simplified method clearly becomes nonconservative, a tuning ratio of greater than one can be regarded as a "critical threshold" beyond which the performance of the simplified method of Makdisi and Seed (1978) may become unreliable and potentially non-conservative.

In addition to the theoretical and experimental studies, some numerical studies also suggest that the simplified methods do not always give a conservative estimate of deformation. For example, in numerical studies performed by Ghanooni and MahinRoosta (2002) on a $115 \mathrm{~m}$ high bituminous core rockfill dam under the effect of an earthquake with $a_{\max }=0.54 \mathrm{~g}$, the displacement of the dam crest was predicted to be $1.2 \mathrm{~m}$ by the stress-deformation analysis while a deformation of around $0.55 \mathrm{~m}$ was estimated by the Makdisi and Seed decoupled method. Feizi-Khankandi et al. (2009) analysed the dynamic behaviour of a $110 \mathrm{~m}$ high rockfill dam under the effect of an earthquake with a magnitude of 7.5 and $a_{\max }=0.54 \mathrm{~g}$. It was shown that the stress-deformation method shows a vertical crest settlement of $1.5 \mathrm{~m}$ with a much larger movement in the direction of the slope, while the Newmark approach leads to $0.8 \mathrm{~m}$ movement of the crest in the direction of the slope of the dam. Nejad et al. $(2010,2011)$ analysed two different dams with heights of $75 \mathrm{~m}$ and $84 \mathrm{~m}$ under an earthquake with a magnitude of 7.5 and $a_{\max }=0.8 \mathrm{~g}$ and showed that the deformations predicted by the stressdeformation analyses are 2 to 4 times larger than those obtained by the Newmark rigid block method and the decoupled Makdisi and Seed method. 
In evaluation of the performance of Tehri Dam with a height of $260 \mathrm{~m}$ under an earthquake with a magnitude 7, Sengupta (2010) reported that the displacement of the dam crest using the Makdisi and Seed method was around half of the deformation obtained from a stressdeformation analysis. Although in another analysis with a stronger earthquake (magnitude 8.5) the Makdisi and Seed method showed an extremely large crest displacement of $7.5 \mathrm{~m}$ while the stress-deformation analysis predicted a settlement of $1.1 \mathrm{~m}$.

Strenk and Wartman (2011) performed a series of probabilistic analyses on the permanent deformations predicted by the Newmark's rigid block and Makdisi-Seed's decoupled methods. The effect of different parameters, such as shear strength parameters, input seismic motion and groundwater level, on the deformation of embankments were studied. Although the results of these analyses were widely scattered, they concluded that the widely accepted notion that these methods could give the crest displacement with accuracy within one order of magnitude may be misleading.

As mentioned before, since the introduction of the sliding block method by Newmark (1965), several attempts have been made to simplify or modify application of the method in practice or include the effects of other important factors. Meehan and Vahedifard (2013) compared the predictions of fifteen of these methods with the displacements records of 122 earth dams and embankments under seismic loading and showed that the results of the simplified methods are not always conservative. The displacements predicted by some of the methods were less than the observed deformations, with differences as high as $1 \mathrm{~m}$ for few cases.

\section{Effects of Tuning Ratio}

As mentioned before, the results of many studies indicate that tuning ratio has a profound effect on the deformation of dams under earthquake loading, but has not been considered in the simplified procedures. Different ranges of tuning ratio where the simplified method 
becomes non-conservative have been proposed by different investigators. This is partially due to uncertainties in calculation of tuning ratio. Different methods can be used to evaluate the fundamental period of a dam, $T_{o}$, many of them are based on simplified assumptions. Also the dynamic behaviour of embankment materials has not been fully understood yet. There are many relationships for dynamic degradation of soil stiffness during cyclic loading, proposed mainly based on laboratory tests on small samples. The choice of degradation relationship influences estimation of the fundamental period of a dam. Inevitably, the range of tuning ratio proposed by different investigators is different.

In order to illustrate the effects of uncertain parameters on tuning ratio, a case will be considered here where application of the simplified methods was found to be non-conservative. The Shur River dam, a $84 \mathrm{~m}$ high asphaltic core rockfill dam shown in Figure 3, was analysed by Nejad et al. (2010), employing both the simplified method and stress-deformation analysis using FLAC. The Mohr-Coulomb constitutive model was used in the analysis, incorporating the stress dependency of the elastic modulus and the degradation of the strain dependent shear modulus and damping during the seismic loading. The earthquake loading used in the dynamic analysis was the East-West component of Gilroy \#1 record of 1989 Loma Prieta earthquake; scaled to have a PGA of $0.8 \mathrm{~g}$. Figure 4 shows the acceleration time history of the earthquake record used in the analysis. It was found that the results of the simplified method are nonconservative compared to the results of the stress-deformation analysis, i.e. the crest settlement predicted by the stress-deformation numerical analyses was more than two to four times that predicted by the simplified methods. It will be of interest to compare the tuning ratio of this dam with the critical threshold proposed by different investigators.

In order to evaluate the tuning ratio for this case, $T_{0}$ and $T_{m}$ should be calculated. The Fourier amplitude transform of the earthquake record is presented in Figure 5, showing that the mean period, $T_{m}$, of the ground motion is $0.39 \mathrm{~s}$. 
To evaluate the fundamental period of the dam an iterative procedure based on the shear beam theory proposed by Makdisi and Seed (1979) is used. The dynamic response of the dam is affected by damping ratio which in turn is a function of the degradation relationship assumed for stiffness of the embankment material. Therefore in the first step, a response spectrum analysis of the dam was performed and the response spectra of the ground motion, $S_{a}$, were evaluated for different damping ratios as shown in Figure 6. The damping ratios considered here are within the normal range employed in the dynamic analysis of embankments.

The dependency of the stiffness and the damping ratio of the embankment material to the level of shear strain causes nonlinearity between the level of excitation and the level of dynamic response. There are many relationships proposed for variation of stiffness, $G$, and damping ratio with respect to shear strain, $\gamma$. In this study four different sets of modulus reduction and damping relationships vs. shear strain for coarse grained materials, proposed by Seed et al. (1986), Shibuya et al. (1990), Ishibashi and Zhang (1993) and Rollins et al. (1998), were used in an equivalent linear approach (Makdisi and Seed 1979) to calculate the relevant dynamic soil properties iteratively, until these properties become compatible with the calculated strain level. . In each step of iteration, an average shear strain is assumed for the dam and corresponding average shear modulus and damping ratio are calculated. Then using the Makdisi and Seed (1979) approach, the fundamental period of the dam and corresponding response spectra based on fundamental period and damping ratio are calculated. Based on the dam height, calculated fundamental period and response spectra, the resultant average shear strain is then calculated and compared with the assumed initial shear strain. The iteration is repeated with the new shear strain level, and continued until acceptable error is achieved. This iterative procedure is illustrated in Figure 7 and the calculated fundamental periods are summarised in Table 2 together with the compatible damping ratio for each case. It can be seen that the calculated fundamental period of the dam varies over a wide range, from $0.39 \mathrm{~s}$ 
to $0.74 \mathrm{~s}$, depending on degradation relationship used. With $T_{m}=0.39 \mathrm{~s}$, the tuning ratio also varies over a range of 1.0 to 1.9 , all greater than the critical threshold above which the simplified method is deemed to be non-conservative.

\section{Proposed Method to Verify the Reliability of the Simplified Methods}

The most important advantage of the simplified methods in deformation analysis under earthquake loading is their simplicity and cost-effectiveness so that they can easily be used as screening tools. Therefore, it is important to know when such a procedure could be relied upon in a systematic engineering design.

Based on the results of recent investigations and the discussions made in the previous sections, it is reasonable to assume that the critical threshold of the tuning ratio beyond which the simplified methods may not be conservative is: $T_{o} / T_{m}>1$. In this section a procedure will be presented through which the tuning ratios for different earthquakes and different dam heights and types are approximated and the conditions beyond which the simplified methods cannot be relied upon will be introduced.

In evaluating the tuning ratio of dams under different earthquake motions, the mean period of the earthquakes, $T_{m}$, should be evaluated. Rathje et al. (1998) used the records of 306 stations from 20 strong earthquakes in regions of active plate-margin of the western United States and developed an empirical relationship that defines the magnitude, distance, and site dependency of the frequency content for different earthquakes. They also proposed a relationship for evaluation of the mean period of earthquakes for shallow crustal earthquakes in stable continental regions (e.g., the eastern United States and Australia). For a dam within $100 \mathrm{~km}$ of a causative fault, which is common in regions with medium to high seismic potentials, the mean period of ground motions for different earthquake magnitudes would be in the range of 
$0.45 \mathrm{~s}$ to $0.8 \mathrm{~s}$ for regions around active plate margins, and between $0.21 \mathrm{~s}$ and $0.45 \mathrm{~s}$ for stable continental regions. Singh and Roy (2009) gathered data on the performances of 152 dams which were subject to deformation during earthquakes. The recorded period of the earthquakes versus distance to epicentre is shown in Figure 8. It shows that around 88 percent of these earthquakes occurred within $100 \mathrm{~km}$ from the dams with mean periods ranging from $0.25 \mathrm{~s}$ to $0.7 \mathrm{~s}$.

Considering the minimum value of the mean period $\left(T_{m}\right)$ of the ground motions within the possible range and assuming the critical threshold of $T_{o} / T_{m}=1$, one could conclude that if the fundamental period of a dam is greater than $0.45 \mathrm{~s}$ in regions of active plate margins and $0.21 \mathrm{~s}$ in stable continental regions, the decoupled approach of Makdisi and Seed may become unreliable.

The fundamental period of a dam can be approximately related to its height and material properties. For a given homogenous triangular shaped earth/rockfill dam with height of $H$, Hatanaka (1955) showed that the fundamental period can be derived from:

$$
T_{o}=2.61 \frac{H}{V_{s}}
$$

where $H$ is the height of the dam and $V_{s}$ is the shear wave velocity of the dam material. For a nonhomogeneous dam modelled as a shear beam, Gazetas (1987) proposed a slightly different equation for $T_{o}$ as:

$$
T_{o}=2.57 \frac{H}{C}
$$

where $C$ is the average shear wave velocity of all materials used in the dam. $V_{s}$ or $C$ could be expressed as a function of the shear modulus, $G$, and mass density, $\rho$, of the material: 


$$
V_{s}=\sqrt{\frac{G}{\rho}}
$$

Gazetas (1987) also proposed an equation for variation of shear modulus along the height of a dam:

$$
G=G_{b}\left(\frac{z}{H}\right)^{\mathrm{m}}
$$

where $G_{b}$ is the average shear modulus at the base of the dam and $z$ is zero at dam crest, increasing to $H$ at the base. The value of $m$ varies between 0.3 and 0.8 . The value of $(z / H)^{\mathrm{m}}$ for a representative point within $z / H$ of 0.5 to 0.67 (between the mid-height and centroid of the dam section) has a mean value of around 0.7 . Therefore, the average shear modulus can be approximated as:

$$
G_{\text {avg }} \approx 0.7 G_{b}
$$

where $G_{b}$ can be taken equal to $G_{\max }$ at the base of the dam. Seed and Idriss (1970) proposed the following relationship for the shear modulus of granular material:

$$
G_{b}=220\left(K_{2 \max }\right)_{\text {avg }}\left(\sigma_{o}\right)^{0.5}
$$

where $\sigma_{o}$ is the average mean effective stress at the base of the dam. $K_{2 \max }$ ranges from 80 to 180 for gravels (Kramer, 1996) and 52 to 70 for sands (Seed and Idriss, 1970). $\left(K_{2 \max }\right)_{\text {avg }}$ represents the mean value of $K_{2 \max }$ for different materials used in the dam. Therefore, the fundamental period of a dam, $T_{o}$ could be calculated as a function of $H, \gamma$, and $\left(K_{2 \max }\right)_{\text {avg }}$ using Equations (1), (3) and (6) which yield: 


$$
T_{o} \approx \frac{0.115 H^{0.75} \gamma^{0.25}}{\sqrt{\left(K_{2 \max }\right)_{\text {avg }}\left(1+2 K_{0}\right)}}
$$

The value of unit weight, $\gamma\left(\right.$ in $\left.\mathrm{kN} / \mathrm{m}^{3}\right)$, and coefficient of lateral pressure, $K_{o}$, can be well approximated within the narrow range appropriate for dam materials and therefore, $T_{o}$ simply becomes a function of dam height $(H$, in meters $)$ and $\left(K_{2 \max }\right)_{\text {avg }}$. The accuracy of such simple function for $T_{o}$ mainly relies on the underpinning simplified theories and field observations as highlighted in derivation, though all approximations are widely accepted in practice. Figure 9 and Figure 10 show the variation of $T_{o}$ as a function of $H$ for two different ranges of $K_{2 \max }$; the range 50 to 80 is more suitable for earthfill dams and the range 90 to 170 is suitable for well compacted rockfill dams. The values of $\gamma$ and $K_{o}$ in these figures are assumed 20 $\mathrm{kN} / \mathrm{m}^{3}$ and 0.5 , respectively. Recalling the critical range of $T_{o}(0.45 \mathrm{~s}$ or $0.21 \mathrm{~s})$, the critical height of dams where the decoupled approach is potentially non-conservative can be obtained from these two figures. In general it can be concluded that in the active seismic regions (e.g. western U.S. and China) the critical height for earthfill dams is between $50 \mathrm{~m}$ and $65 \mathrm{~m}$ and for rockfill dams is between $75 \mathrm{~m}$ and $110 \mathrm{~m}$. Similarly, in the stable continental regions (e.g. Australia) the critical heights are between $20 \mathrm{~m}$ and $30 \mathrm{~m}$ for earthfill dams and between $30 \mathrm{~m}$ and $45 \mathrm{~m}$ for rockfill dams. Note that in the development of Makdisi and Seed's method, the maximum dam height was limited to $60 \mathrm{~m}$ and therefore the effects of tuning ratio, for earthquakes in the active seismic regions of US, could not be detected by the method.

\section{Application in Practice - Case Study of Zipingpu Dam}

In this section the results of deformation analyses using the Newmark rigid block method and the Makdisi and Seed decoupled method are compared with the observed deformation of a 
large rockfill dam in order to evaluate the reliability guideline proposed in the previous section.

Zipingpu dam is one of the largest modern concrete face rockfill dams in the world which experienced a severe earthquake and suffered substantial internal deformation and crest displacement. The '5.12' Wenchuan Earthquake hit this dam severely in May 2008 and caused relatively large permanent displacements to the dam (Kong et al. 2010). A cross section of the dam at its deepest point is shown in Figure 11. The maximum height of the dam is $156 \mathrm{~m}$, with a $664 \mathrm{~m}$ long $12 \mathrm{~m}$ wide crest. The upstream slope of the dam is $1 \mathrm{~V}: 1.4 \mathrm{H}$. Two downstream berms at EL. 796.0 and $840.0 \mathrm{~m}$ with a width of $6 \mathrm{~m}$ provide an average downstream slope of $1 \mathrm{~V}: 1.5 \mathrm{H}$ (Xu et al., 2012). The '5.12' Wenchuan Earthquake had a magnitude of about 8 on the Richter scale and rendered a maximum permanent settlement of $1 \mathrm{~m}$ and a horizontal displacement of $0.6 \mathrm{~m}$ to the dam crest (Chen and Han 2009). The time history of the earthquake acceleration recorded in Mao Town, shown in Figure 12, is adopted here as the base ground motion for the dam. The record is a bedrock acceleration time history recorded $75 \mathrm{~km}$ from the Zipingpu dam and scaled to attain a PGA of $0.55 \mathrm{~g}$, following Zou et al. (2013). This is an 80 seconds long record with high frequency content and an extremely low predominant period of 0.12 seconds, as shown in Figure 13.

To calculate the deformation of the dam using the Makdisi and Seed decoupled method, four sliding blocks on the downstream side of the dam are taken into account as shown in Figure 14(a). In order to calculate the yield acceleration for each sliding block, pseudo-static analyses are performed. Following Kan and Taiebat (2015), the unit weight of the rockfill material is $21.6 \mathrm{kN} / \mathrm{m}^{3}$, the peak friction angle of the rockfill is taken as $45^{\circ}$ and a nominal small cohesion of $15 \mathrm{kPa}$ is assumed to prevent failure of very shallow sliding blocks in the analyses. The pseudo-static analyses are performed using the Spencer method in Slope/W (Geo-Slope International Ltd. 2007). The horizontal yield acceleration which brings a block to 
the onset of failure is found by a trial and error approach and presented for each block in Figure 14(a).

To calculate the induced acceleration on each sliding block due to the earthquake, a simple stress-deformation analysis is performed on the dam in FLAC 2D (Itasca Consulting Group Inc. 2008), utilizing an equivalent linear constitutive model for the rockfill material (Kan and Taiebat 2015). The elastic shear modulus is evaluated from the equation proposed by Kokusho and Esashi (1981) for coarse gravels:

$$
G_{\max }=\frac{13000(2.17-e)^{2}}{1+e}\left(\sigma_{o}\right)^{0.55}
$$

where $G_{\max }$ is the small strain shear modulus, $\sigma_{0}$ is the mean effective stress and $e$ is the void ratio. Values of $G_{\max }$ are calculated for each element using the actual value of $\sigma_{0}$ and $e$ evaluated after the reservoir impoundment. The small strain bulk modulus is also calculated using the theory of elasticity assuming a Poisson's ratio of 0.3 for rockfill materials. These small strain elastic parameters are subjected to degradation at higher shear strains when the material undergoes cyclic loading. The degradation function is assumed to follow the upperbound curve proposed by Seed and Idriss (1970) for granular materials.

The average induced acceleration on a block at any time is calculated as the weighted average of the accelerations of all grid points inside the block obtained by the equivalent linear model. For example, the average induced acceleration calculated for block \#4 is shown in Figure 14(b). Also shown in Figure 14(c) is the time history of the permanent displacement of sliding blocks \#2 to \#4. Note that the computed displacement of sliding block \#1 is almost zero. The maximum permanent horizontal displacement for block $\# 4$ is calculated as $0.14 \mathrm{~m}$ which is clearly much less than that observed in the field. 
As was discussed before, many analytical models have been proposed based on the Newmark sliding block concept in order to simplify the application of the method using a single equation. It is of interest to study the performance of these models in predicting the behaviour of Zipingpu dam. Table 3 lists some of these models and their required parameters and main area of their applications. All these models are used to predict the displacement of Zipingpu dam under the earthquake loading. The values of different parameters required by these models are listed in Table 4. The predicted displacements obtained from these models are listed in the last column of Table 3 and shown graphically in Figure 15, where all displacements are consistently projected along the slope batters of the dam. For a few of the predictive models where a range and a median value for displacements are suggested (e.g. Hynes-Griffin and Franklin 1984, Jibson 2007) the most conservative predicted value in upper range is reported in this paper. It can be seen that the displacements predicted by most of these models are less than the observed displacement, with the exception of Bray and Travasarou (2007) model which over-predicts the displacement by $60 \%$.

The reliability of the simplified methods in calculating the deformation of Zipingpu dam can be evaluated according to the guideline presented in current study. The fundamental period of the dam is calculated as $0.753 \mathrm{~s}$ using the procedure outlined in Makdisi and Seed (1979). The mean period of the Wenchuan earthquake is 0.21 second. Therefore, the tuning ratio $\left(T_{o} / T_{m}\right)$ of the system is around 3.6, which is much higher than the critical threshold of 1. Figure 10 also shows that the fundamental period and height of the Zipingpu dam is on the range where application of the simplified methods is non-conservative for active seismic regions.

\section{Summary and Conclusions}

The simplified methods, especially the method presented by Makdisi and Seed (1978), are widely used in practice to evaluate the deformation of embankment dams under earthquake 
loading. This method is relatively simple and inexpensive in comparison with the complicated numerical methods. It is also recommended by some codes and guidelines to be used as a screening tool to identify cases with marginal safety for which a more accurate method could be utilised. This is acceptable only if it is assumed that this method gives a conservative estimate of crest deformations. Nevertheless, recent stress-deformation analyses and theoretical investigations show cases where this method is not conservative.

Based on theoretical and experimental studies, it is concluded that the simplified methods is potentially non-conservative when the tuning ratio $\left(T_{o} / T_{m}\right)$ is greater than the critical threshold of unity. Based on this assumption, a set of charts is presented, for different types of dams and different seismic regions, which define the range of height-to-fundamental period of dams for which the simplified method is reliable and conservative. These charts show that the simplified method of Makdisi and Seed (1978) is potentially non-conservative for embankment dams higher than $50 \mathrm{~m}$ in the active seismic regions and higher than $20 \mathrm{~m}$ in the stable seismic regions.

The reliability of Makdisi and Seed method in predicting the deformation of the Zipingpu dam is also discussed. It is shown that the decoupled approach gives a crest displacement much less than those observed in the field. The majority of other models proposed based on the concept of the Newmark sliding block also fail to predict a conservative displacement for the Zipingpu dam. This can be attributed to the nature of the input motion which has a very high frequency, rendering a tuning ratio much higher than 1.0.

It should be noted that the critical threshold of the tuning ratio selected in this study is based on previous investigations which were mainly focused on natural slopes and landfills. Therefore it would be necessary to study the effects of the tuning ratio on seismic performance of dams more specifically and to be able to evaluate the critical threshold for dams more accurately. 
The proposed framework in this paper to assess the reliability of Newmark-type methods for evaluation of seismic-induced displacement of the embankments is a general approach in concept, based on the characteristics of the input seismic motion (depicted in $T_{m}$ ) and geometry and material type of the dam (represented by $T_{o}$ ). However, application of the derived critical dam heights for design of embankments in active seismic regions and stable continental regions shall be considered within the limitations of the underpinning data and simplifications in calculation of the fundamental period of the dam.

\section{Acknowledgement}

The digitized record of the 5.12 Wenchuan earthquake as recorded in Mao Town was kindly provided by Prof. Degao Zou from Dalian University of Technology which is gratefully acknowledged. 


\section{References}

Ambraseys, N., and Menu, J. 1988. Earthquake induced ground displacements. Earthquake Engineering \& Structural Dynamics, 16, 985-1006.

Ambraseys, N., and Sarma, S. K. 1967. Response of of Earth Dams to Strong Earthquaes. Geotechnique, 17, 181-213.

ANCOLD 1998. Guidelines for design of dams for earthquake, Melbourne, Australian National Committee on Large Dams.

Bray, J., Rathje, E., Augello, A., and Merry, S. 1998. Simplified seismic design procedure for geosynthetic-lined, solid-waste landfills. Geosynthetics International, 5, 203-235.

Bray, J., and Travasarou, T. 2007. Simplified procedure for estimating earthquake-induced deviatoric slope displacements. Journal of Geotechnical and Geoenvironmental Engineering, 133, 381-392.

Chen, S.-S., and Han, H.-Q. 2009. Impact of the '5.12' Wenchuan earthquake on Zipingpu concrete face rock-fill dam and its analysis. Geomechanics and Geoengineering: An International Journal, 4, 299-306.

Feizi-Khankandi, S., Ghalandarzadeh, A., Mirghasemi, A. A., and Hoeg, K. 2009. Seismic Analysis of the Garmrood Embankment Dam with Asphaltic Concrete Core. Soils and Foundations, 49, 153-166.

Franklin, A. G., and Chang, F. K. 1977. Earthquake resistance of earth and rock-fill dams. Report 5: Permanent displacements of earth embankments by Newmark sliding block analysis, Misc. Paper S-71-17. Vicksburg: US Army Engineer Waterways Experiment Station.

Gazetas, G. 1987. Seismic response of earth dams: some recent developments. Soil Dynamics and Earthquake Engineering, 6, 2-47.

Geo-Slope International Ltd. 2007. GeoStudio User's Manual Calgary, Alberta, Canada T2P 2 Y5.

Ghanooni, S., and Mahin Roosta, R. 2002. Seismic analysis and design of asphaltic concrete core dams. Journal of Hydropower and Dams, 9, 75-78.

Hatanaka, M. 1955. Fundamental Considerations on the Earthquake Resistant Properties of the Earth Dam. Part I On the Vibration of Earth Dam. Bulletins-Disaster Prevention Research Institute, Kyoto University, 11, 1-22.

Hynes-Griffin, M., and Franklin, A. 1984. Rationalizing the seismic coefficient method. Miscellaneous paper GL-84-13. US Army Corps of Engineers Waterways Experiment Station, Vicksburg, Mississippi.

Ishibashi, I., and Zhang, X. 1993. Unified dynamic shear moduli and damping ratios of sand and clay. Soils and Foundations 33, 182-191. 
Itasca Consulting Group Inc. 2008. FLAC-Fast Lagrangian Analysis of Continua, Ver. 6.0, Minneapolis, MN (USA).

Jibson, R. W. 2007. Regression models for estimating coseismic landslide displacement. Engineering Geology, 91, 209-218.

Kan, M. E., and Taiebat, H. A. 2015. Application of advanced bounding surface plasticity model in static and seismic analyses of Zipingpu Dam. Canadian Geotechnical Journal, 1-17.

Kokusho, T., and Esashi, Y. 1981. Cyclic triaxial test on sands and coarse materials. Proceedings of the 10th International Conference on Soil Mechanics and Foundation Engineering. Stockholm.

Kong, X.-J., Zhou, Y., Xu, B., and Zou, D.-G. 2010. Analysis on seismic failure mechanism of zipingpu dam and several reflections of aseismic design for high rock-fill dam. Proceedings of the 12th International Conference on Engineering, Science, Construction, and Operations in Challenging Environments - Earth and Space ASCE.

Kramer, S. L. 1996. Geotechnical Earthquake Engineering, Prentice Hall, Upper Saddle River, NJ.

Kramer, S. L., and Smith, M. W. 1997. Modified Newmark model for seismic displacements of compliant slopes. Journal of Geotechnical and Geoenvironmental Engineering, $123,635-644$.

Makdisi, F. I., and Seed, H. B. 1978. Simplified procedures for estimating dam and embankment earthquake induced deformations. Journal of the Geotechnical Engineering Division-Asce, 104, 849-867.

Makdisi, F. I., and Seed, H. B. 1979. Simplified procedure for evaluating embankment response. Journal of the Geotechnical Engineering Division-Asce, 105, 1427-1434.

Meehan, C. L., and Vahedifard, F. 2013. Evaluation of simplified methods for predicting earthquake-induced slope displacements in earth dams and embankments. Engineering Geology, 152, 180-193.

Nejad, B. G., Soden, P., Taiebat, H., and Murphy, S. 2010. Seismic deformation analysis of a rockfill dam with a bituminous concrete core. 9th World Congress on Computational Mechanics and 4th Asian Pacific Conference on Computational Mechanics. Australia: IOP Publishing.

Nejad, B. G., Taiebat, H. A., Noske, C., and Murphy, D. 2011. Seismic response and dynamic deformation analysis of Sar-Cheshmeh tailings dam. Proceedings of the $2 n d$ International FLAC/DEM Symposium in Numerical Modeling. Melbourne, Australia: Itasca.

Newmark, N. M. 1965. Effects of earthquakes on dams and embankments. Geotechnique, 15, 139-160.

Rathje, E. M., Abrahamson, N. A., and Bray, J. D. 1998. Simplified frequency content estimates of earthquake ground motions. Journal of Geotechnical and Geoenvironmental Engineering, 124, 150-159. 
Rathje, E. M., and Antonakos, G. 2011. A unified model for predicting earthquake-induced sliding displacements of rigid and flexible slopes. Engineering Geology, 122, 51-60.

Rathje, E. M., and Bray, J. D. 1999. An examination of simplified earthquake-induced displacement procedures for earth structures. Canadian Geotechnical Journal, 36, $72-87$.

Rathje, E. M., and Bray, J. D. 2000. Nonlinear coupled seismic sliding analysis of earth structures. Journal of Geotechnical and Geoenvironmental Engineering, 126, 10021014.

Richards, R., and Elms, D. G. 1979. Seismic behavior of gravity retaining walls. Journal of the Geotechnical Engineering Division, ASCE 105 449-464.

Rollins, K. M., Evans, M. D., and Diehl, N. B. 1998. Shear modulus and damping relationships for gravels. Journal of Geotechnical and Geoenvironmental Engineering, 124, 396.

Sarma, S. K. 1975. Seismic stability of earth dams and embankments. Geotechnique, 25, 743-761.

Saygili, G., and Rathje, E. M. 2008. Empirical predictive models for earthquake-induced sliding displacements of slopes. Journal of Geotechnical and Geoenvironmental Engineering, 134, 790-803.

Seed, H., Wong, R., Idriss, I., and Tokimatsu, K. 1986. Moduli and damping factors for dynamic analyses of cohesive soils. Journal of Geotechnical Engineering, ASCE, 112, 1016-1032.

Seed, H. B., and Idriss, I. M. 1970. Soil moduli and damping factors for dynamic response analysis, Report No. EERC 70-10. Earthquake Engineering Research Center, University of California, Berkeley.

Sengupta, A. 2010. Estimation of permanent displacements of the Tehri dam in the Himalayas due to future strong earthquakes. Sadhana-Academy Proceedings in Engineering Sciences, 35, 373-392.

Shibuya, S., Kong, X., and Tatsuoka, F. Deformation characteristics of gravels subjected to monotonic and cyclic loading. Proc., 8th Japan Earthquake Engineering Symp., 1990 Tokyo, Japan. 771-776.

Singh, R., and Roy, D. 2009. Estimation of Earthquake-Induced Crest Settlements of Embankments. Am. J. Engg. \& Applied Sci, 2, 515-525.

Strenk, P. M., and Wartman, J. 2011. Uncertainty in seismic slope deformation model predictions. Engineering Geology, 122, 61-72.

Swaisgood, J. 2003. Embankment dam deformations caused by earthquakes. Proceedings of the 2003 Pacific conference on earthquake engineering. Christchurch, NZ.

Wartman, J., Bray, J. D., and Seed, R. B. 2003. Inclined plane studies of the Newmark sliding block procedure. Journal of Geotechnical and Geoenvironmental Engineering, 129, 673-684. 
Watson-Lamprey, J., and Abrahamson, N. 2006. Selection of ground motion time series and limits on scaling. Soil Dynamics and Earthquake Engineering, 26, 477-482.

$\mathrm{Xu}, \mathrm{B}$, Zou, D., and Liu, H. 2012. Three-dimensional simulation of the construction process of the Zipingpu concrete face rockfill dam based on a generalized plasticity model. Computers and Geotechnics, 43, 143-154.

Yegian, M. K., Marciano, E. A., and Ghahraman, V. G. 1991. Earthquake-induced permanent deformations: probabilistic approach. Journal of Geotechnical Engineering, 117, 18-34.

Zou, D., Xu, B., Kong, X., Liu, H., and Zhou, Y. 2013. Numerical simulation of the seismic response of the Zipingpu concrete face rockfill dam during the Wenchuan earthquake based on a generalized plasticity model. Computers and Geotechnics, 49, 111-122. 


\section{List of Figures}

Figure 1: Major deformation patterns in earth dams due to lateral spreading (modified after Ambraseys, 1959)

Figure 2: Concepts of the Newmark approach (modified after Newmark, 1965)

Figure 3: Cross section of the $84 \mathrm{~m}$ high Shur River dam (modified after Nejad et al. 2010)

Figure 4: Acceleration time history of Loma Prieta Earthquake (E-W record, Gilroy \#1 station, scaled to $0.8 \mathrm{~g})$

Figure 5: Fourier amplitude transform of the Loma Prieta earthquake record

Figure 6: Response spectra of the Loma Prieta earthquake for different damping ratios

Figure 7: Iterative procedure of equivalent linear approach using four stress-strain dependencies

Figure 8: Variation of the predominant period of earthquakes vs. distance (data from Singh and Roy 2009)

Figure 9: Variation of fundamental period with height for earthfill dams

Figure 10: Variation of fundamental period with height for rockfill dams

Figure 11: Typical cross section of Zipingpu dam (cross section 0+251, all units in Meters)

Figure 12: Acceleration time history of the E-W component of the " 5.12 " earthquake as recorded in Mao Town and scaled to $0.55 \mathrm{~g}$

Figure 13: Response spectra of the "5.12" earthquake (Mao Town record)

Figure 14: Simplified seismic analysis of Zipingpu dam, (a) location of the four sliding blocks, (b) acceleration time history for block \#4, and (c) displacement time history for blocks \#2, \#3, \#4

Figure 15: Observed vs predicted displacements of Zipingpu dam obtained from simplified models 


\section{List of Tables}

Table 1: Summary of previous theoretical studies on reliability of the simplified methods

Table 2: Tuning ratio of Shur River dam calculated based on four different stiffness functions

Table 3: Different simplified models, their main parameters, and their prediction of displacements of Zipingpu dam

Table 4: Parameters of different simplified models, their definitions, and the values used in calculation of displacement of Zipingpu dam 
Table 1: Summary of previous theoretical studies on reliability of the simplified methods

\begin{tabular}{|c|c|c|}
\hline Reference & $\begin{array}{l}\text { Rigid Block Analysis } \\
\text { (e.g. Newmark, 1965) }\end{array}$ & $\begin{array}{l}\text { Decoupled Analysis } \\
\text { (e.g. Makdisi and Seed, 1978) }\end{array}$ \\
\hline $\begin{array}{l}\text { Rathje and Bray } \\
\text { (1999) }\end{array}$ & $\begin{array}{c}\text { Non-conservative for } \\
0.2<\mathrm{T}_{\mathrm{o}} / \mathrm{T}_{\mathrm{m}}<2 \sim 3\end{array}$ & $\begin{array}{c}\text { Conservative for } \mathrm{T}_{\mathrm{o}} / \mathrm{T}_{\mathrm{m}}<2 \text { and } \mathrm{k}_{\mathrm{y}} / \mathrm{k}_{\max }<0.6 \\
\text { Non-conservative for } \mathrm{T}_{\mathrm{o}} / \mathrm{T}_{\mathrm{m}}>4\end{array}$ \\
\hline $\begin{array}{l}\text { Rathje and Bray } \\
\qquad(2000)\end{array}$ & $\begin{array}{l}\text { Significantly non-conservative } \\
\text { or conservative }\end{array}$ & $\begin{array}{c}\text { Conservative for } \mathrm{T}_{\mathrm{o}} / \mathrm{T}_{\mathrm{m}}<1 \\
\text { May be non-conservative for } \mathrm{T}_{\mathrm{o}} / \mathrm{T}_{\mathrm{m}}>1 \\
\text { Potentially non-conservative for large } \\
\mathrm{T}_{\mathrm{o}} / \mathrm{T}_{\mathrm{m}} \text {, and } \mathrm{k}_{\mathrm{y}} / \mathrm{k}_{\max }>0.4 \\
\text { Primarily non-conservative for large } \\
\mathrm{T}_{\mathrm{o}} / \mathrm{T}_{\mathrm{m}} \text {, low } \mathrm{k}_{\mathrm{y}} \text { and intense ground motion }\end{array}$ \\
\hline $\begin{array}{l}\text { Wartman et } \\
\text { al.(2003) }\end{array}$ & $\begin{array}{l}\text { non-conservative for } \\
0.2 \leq \text { tuning ratio } \leq 1.3\end{array}$ & - \\
\hline
\end{tabular}


Table 2: Tuning ratio of Shur River dam calculated based on four different stiffness functions

\begin{tabular}{c|ccccc}
\hline $\begin{array}{c}\text { Stress- Strain } \\
\text { Dependency }\end{array}$ & $\begin{array}{c}\text { Seed et al. } \\
(1986)\end{array}$ & $\begin{array}{c}\text { Shibuya et } \\
\text { al. }(1990)\end{array}$ & $\begin{array}{c}\text { Ishibashi and } \\
\text { Zhang } \\
(1993)\end{array}$ & $\begin{array}{c}\text { Rollins et } \\
\text { al.(1998) }\end{array}$ & Average \\
\hline$T_{0}$ (Second) & 0.74 & 0.41 & 0.39 & 0.60 & 0.54 \\
\hline$S_{a}\left(T=T_{0}\right)(\mathrm{g})$ & 0.51 & 3.15 & 3.27 & 0.89 & 1.96 \\
\hline Damping (\%) & 15.31 & 5.51 & 5.78 & 10.99 & 9.4 \\
\hline$T_{0} / T_{m}$ & 1.90 & 1.05 & 1.00 & 1.54 & 1.38 \\
\hline
\end{tabular}


Table 3: Different simplified models, their main parameters, and their prediction of displacements of Zipingpu dam

\begin{tabular}{|c|c|c|c|}
\hline Reference & $\begin{array}{l}\text { Parameters } \\
\text { incorporated }\end{array}$ & Main application & $\begin{array}{l}\text { Predicted } \\
\text { displacement (cm) }\end{array}$ \\
\hline $\begin{array}{l}\text { Franklin and Chang } \\
(1977)\end{array}$ & $v_{\max }, a_{\max }, a_{y}$ & Earth embankments & 4.0 \\
\hline $\begin{array}{l}\text { Makdisi and Seed } \\
(1978)\end{array}$ & Decoupled & $\begin{array}{l}\text { Earth dams and } \\
\text { embankments }\end{array}$ & 14.1 \\
\hline $\begin{array}{l}\text { Richards and Elms } \\
(1979)\end{array}$ & $v_{\max }, a_{\max }, a_{y}$ & Gravity structures & 3.9 \\
\hline $\begin{array}{l}\text { Hynes-Griffin and } \\
\text { Franklin (1984) }\end{array}$ & $a_{\max }, a_{y}$ & Earth dams & 0.7 \\
\hline $\begin{array}{l}\text { Ambraseys and } \\
\text { Menu (1988) }\end{array}$ & $a_{\max }, a_{y}$ & Ground and slopes & 3.3 \\
\hline Yegian et al. (1991) & $a_{\max }, a_{y}, T_{o}, N_{e q}$ & $\begin{array}{l}\text { Earth dams and } \\
\text { embankments }\end{array}$ & 47.7 \\
\hline Bray et al. (1998) & $a_{\max }, a_{y}, k_{\max }, D_{5-95}$ & Landfill slopes & 9.3 \\
\hline $\begin{array}{l}\text { Watson-Lamprey and } \\
\text { Abrahamson (2006) }\end{array}$ & $\begin{array}{l}S_{a}(T=1 s), A_{R M S} \\
a_{\max }, D u r_{a c}, a_{y}\end{array}$ & Earth slopes & 1.8 \\
\hline $\begin{array}{l}\text { Bray and Travasarou } \\
(2007)\end{array}$ & $\begin{array}{l}k_{y}, S_{a}\left(T=1.5 T_{s}\right) \\
T_{s}, M\end{array}$ & $\begin{array}{l}\text { Earth and waste } \\
\text { slopes }\end{array}$ & 161.3 \\
\hline \multirow{4}{*}{ Jibson (2007) } & $a_{\max }, a_{y}$ & \multirow{4}{*}{ Natural slopes } & 3.3 \\
\hline & $a_{\max }, a_{y}, M$ & & 8.7 \\
\hline & $I_{a}, a_{y}$ & & 0.04 \\
\hline & $I_{a}, a_{\max }, a_{y}$ & & 9.6 \\
\hline $\begin{array}{l}\text { Saygili and Rathje } \\
(2008)\end{array}$ & $a_{\max }, a_{y}, v_{\max }$ & Natural slopes & 3.7 \\
\hline $\begin{array}{l}\text { Rathje and } \\
\text { Antonakos (2011) }\end{array}$ & $k_{\max }, k_{y}, k_{\max -v e l}, T_{s}$ & Natural slopes & 0.5 \\
\hline
\end{tabular}


Table 4: Parameters of different simplified models, their definitions, and the values used in calculation of displacement of Zipingpu dam

\begin{tabular}{|c|c|c|c|}
\hline Parameter & \multicolumn{2}{|l|}{ Definition } & Value \\
\hline$a_{\max }\left(\mathrm{m} / \mathrm{s}^{2}\right)$ & \multicolumn{2}{|c|}{ Peak horizontal ground acceleration } & 5.5 \\
\hline$a_{y}\left(\mathrm{~m} / \mathrm{s}^{2}\right)$ & \multicolumn{2}{|c|}{$\begin{array}{l}\text { Critical or yield acceleration for sliding block with minimum factor of } \\
\text { safety (FS) }\end{array}$} & 2.65 \\
\hline \multirow{2}{*}{$k_{\max }(\mathrm{g})$} & \multirow{2}{*}{$\begin{array}{l}\text { Maximum induced seismic } \\
\text { coefficient on sliding block }\end{array}$} & Bray et al. (1998) & 0.15 \\
\hline & & Rathje and Antonakos (2011) & 0.05 \\
\hline$k_{y}(\mathrm{~g})$ & \multicolumn{2}{|l|}{ Critical or yield coefficient } & 0.265 \\
\hline$T_{p}(\mathrm{~s})$ & \multicolumn{2}{|c|}{ Predominant period of earthquake acceleration record } & 0.12 \\
\hline$T_{m}(\mathrm{~s})$ & \multicolumn{2}{|c|}{ Mean period of earthquake acceleration record } & 0.208 \\
\hline$T_{o}(\mathrm{~s})$ & \multicolumn{2}{|c|}{ Fundamental period of the slope } & 0.753 \\
\hline$T_{s}(\mathrm{~s})$ & \multicolumn{2}{|c|}{ Natural period of the sliding block } & 0.931 \\
\hline$v_{\max }(\mathrm{cm} / \mathrm{s})$ & \multicolumn{2}{|l|}{ Peak ground velocity } & 36.3 \\
\hline$k_{\max -v e l}(\mathrm{~cm} / \mathrm{s})$ & \multicolumn{2}{|l|}{ Peak velocity on sliding block } & 11.5 \\
\hline$N_{e q}$ & \multicolumn{2}{|c|}{ Equivalent number of uniform cycles } & 21 \\
\hline$D_{5-95}(\mathrm{~s})$ & \multicolumn{2}{|c|}{ Time between $5 \%$ and $95 \%$ of the Arias intensity of earthquake } & 39.71 \\
\hline $\begin{array}{l}S_{a}(T=1 s) \\
\left(\mathrm{m} / \mathrm{s}^{2}\right)\end{array}$ & \multicolumn{2}{|c|}{ Spectral acceleration with 5\% damping at 1 second } & 2.466 \\
\hline $\begin{array}{l}S_{a}\left(T=1.5 T_{s}\right) \\
\left(\mathrm{m} / \mathrm{s}^{2}\right)\end{array}$ & \multicolumn{2}{|c|}{$\begin{array}{l}\text { Spectral acceleration with } 5 \% \text { damping at degraded period } \\
\text { equal to } 1.5 T_{s}\end{array}$} & 1.871 \\
\hline$A_{R M S}\left(\mathrm{~m} / \mathrm{s}^{2}\right)$ & \multicolumn{2}{|c|}{ Root mean square of acceleration } & 1.018 \\
\hline$D u r_{a c}(\mathrm{~s})$ & \multicolumn{2}{|c|}{$\begin{array}{l}\text { Duration for which the acceleration is greater than the yield } \\
\text { acceleration }\end{array}$} & 1.43 \\
\hline$M$ (Richter) & \multicolumn{2}{|l|}{ Earthquake magnitude } & 8 \\
\hline$I_{a}(\mathrm{~m} / \mathrm{s})$ & \multicolumn{2}{|l|}{ Arias intensity } & 13.11 \\
\hline
\end{tabular}




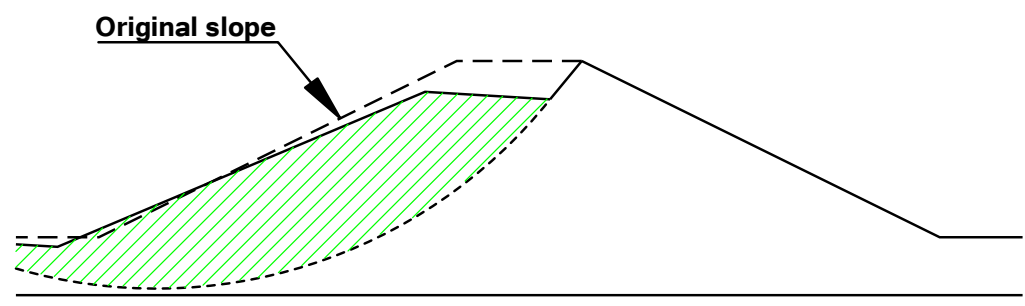

First Shock
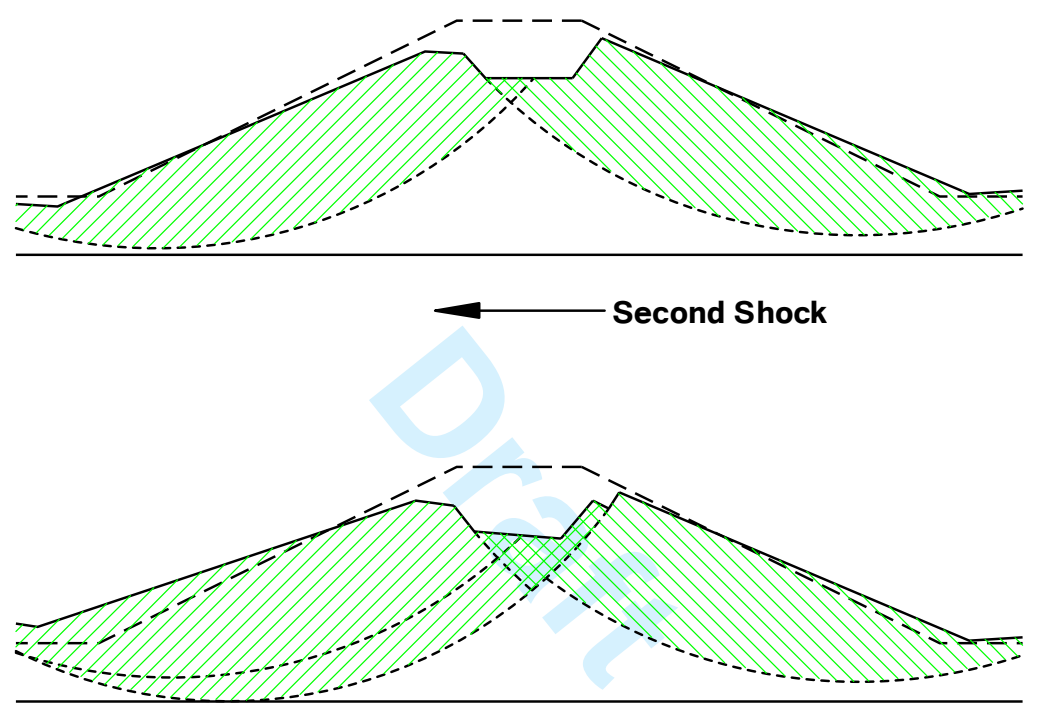

Third Shock

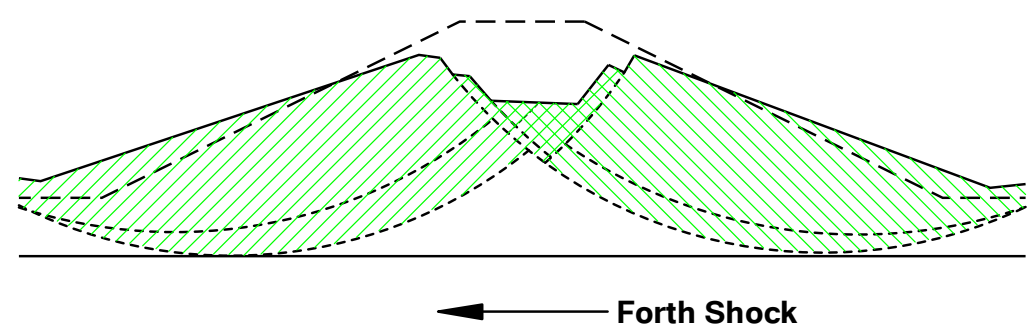

Figure 1: Major deformation patterns in earth dams due to lateral spreading (modified after Ambraseys, 1959) 


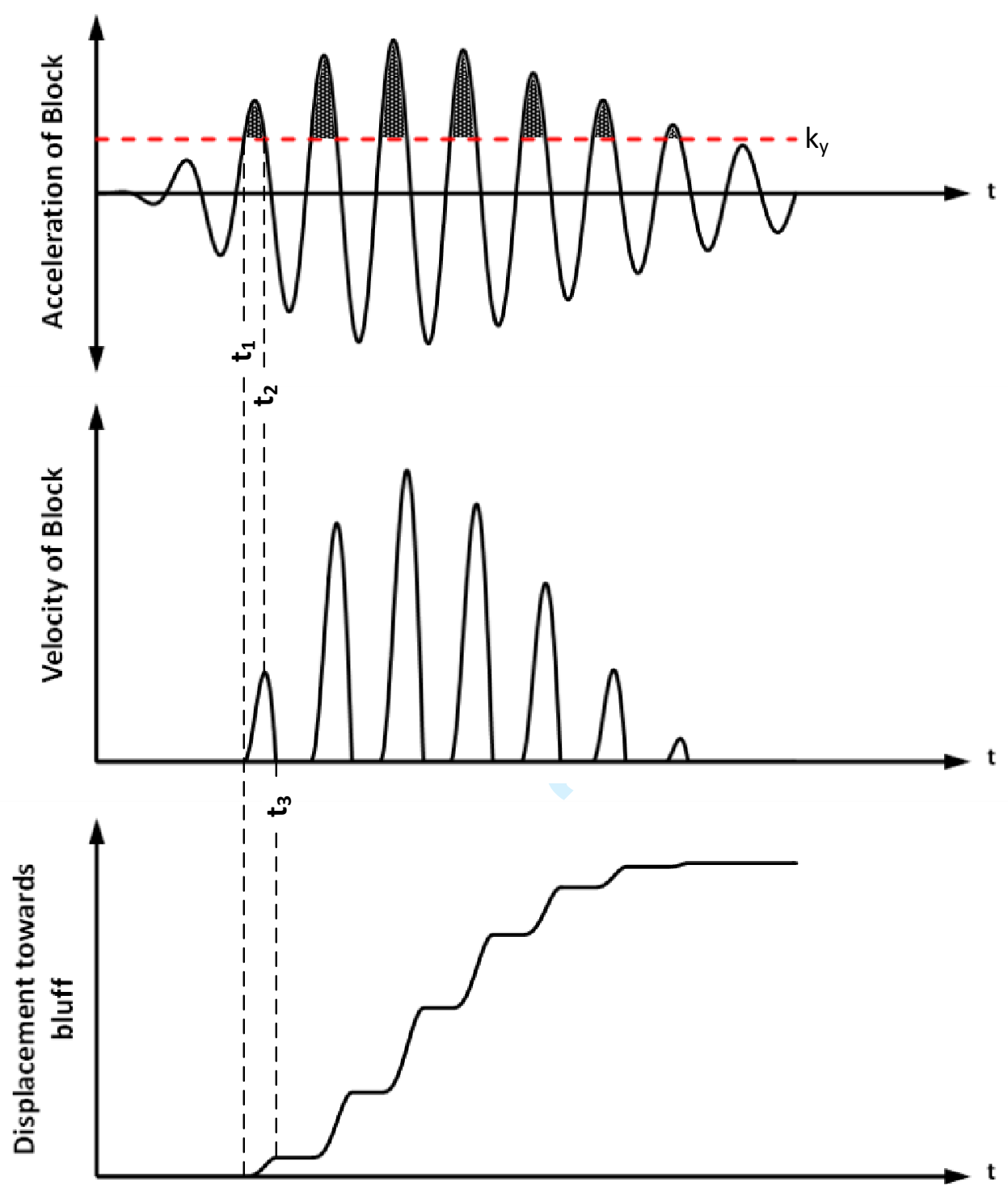

Figure 2: Concepts of the Newmark approach

(modified after Newmark, 1965) 


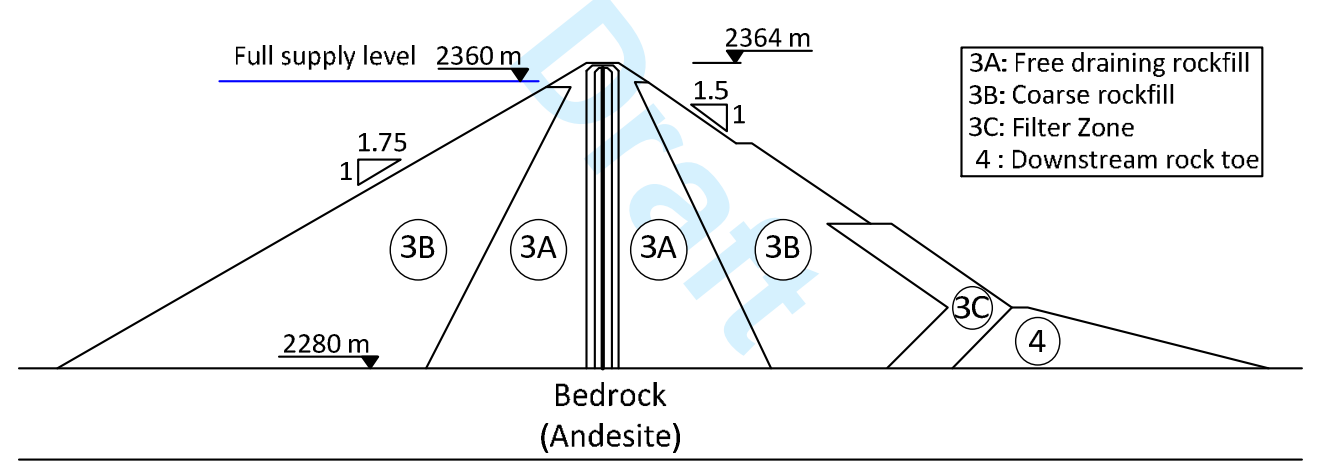

Figure 3: Cross section of the $84 \mathrm{~m}$ high Shur River dam

(modified after Nejad et al. 2010) 


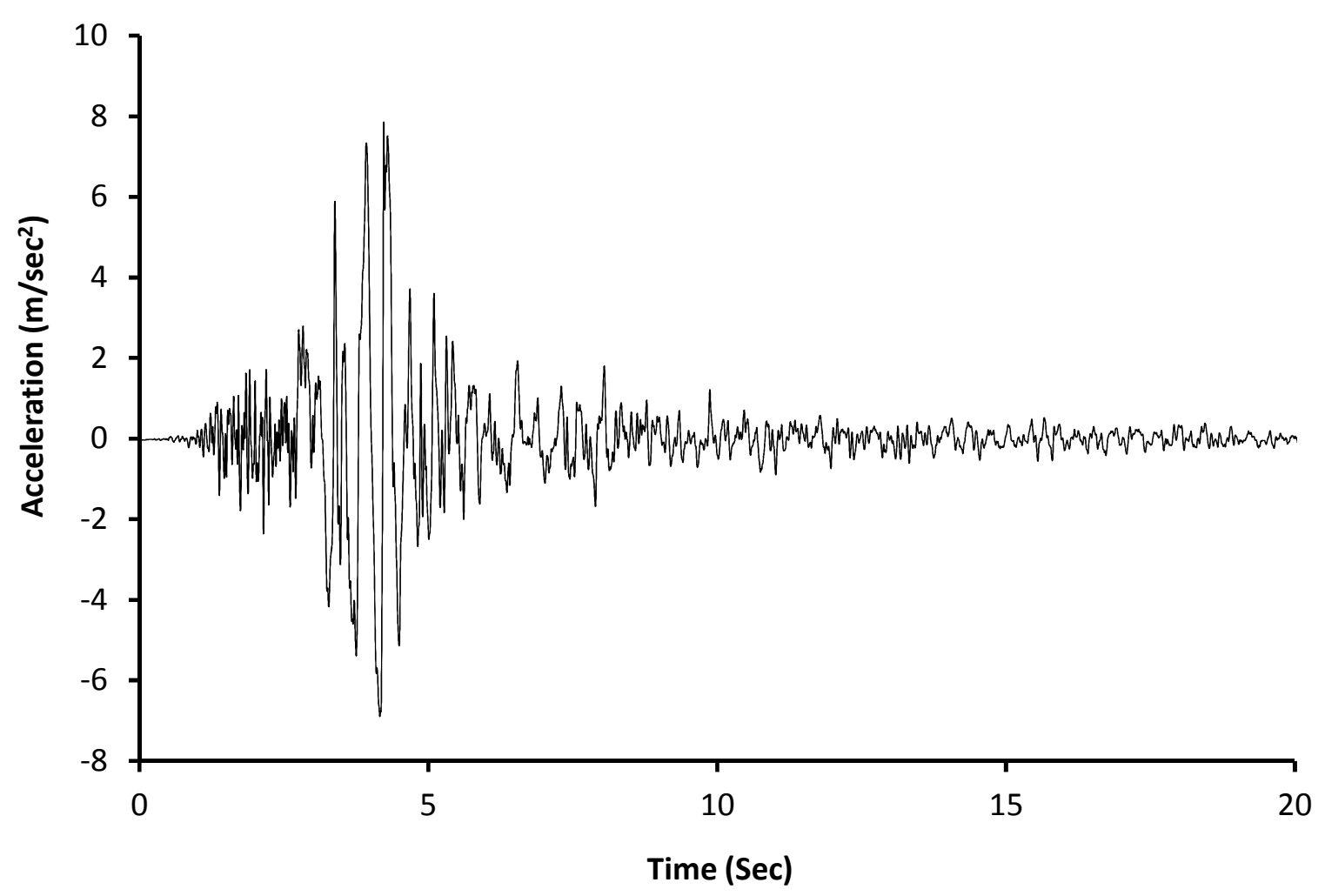

Figure 4: Acceleration time history of Loma Prieta Earthquake (E-W record, Gilroy \#1 station, scaled to $0.8 \mathrm{~g}$ ) 


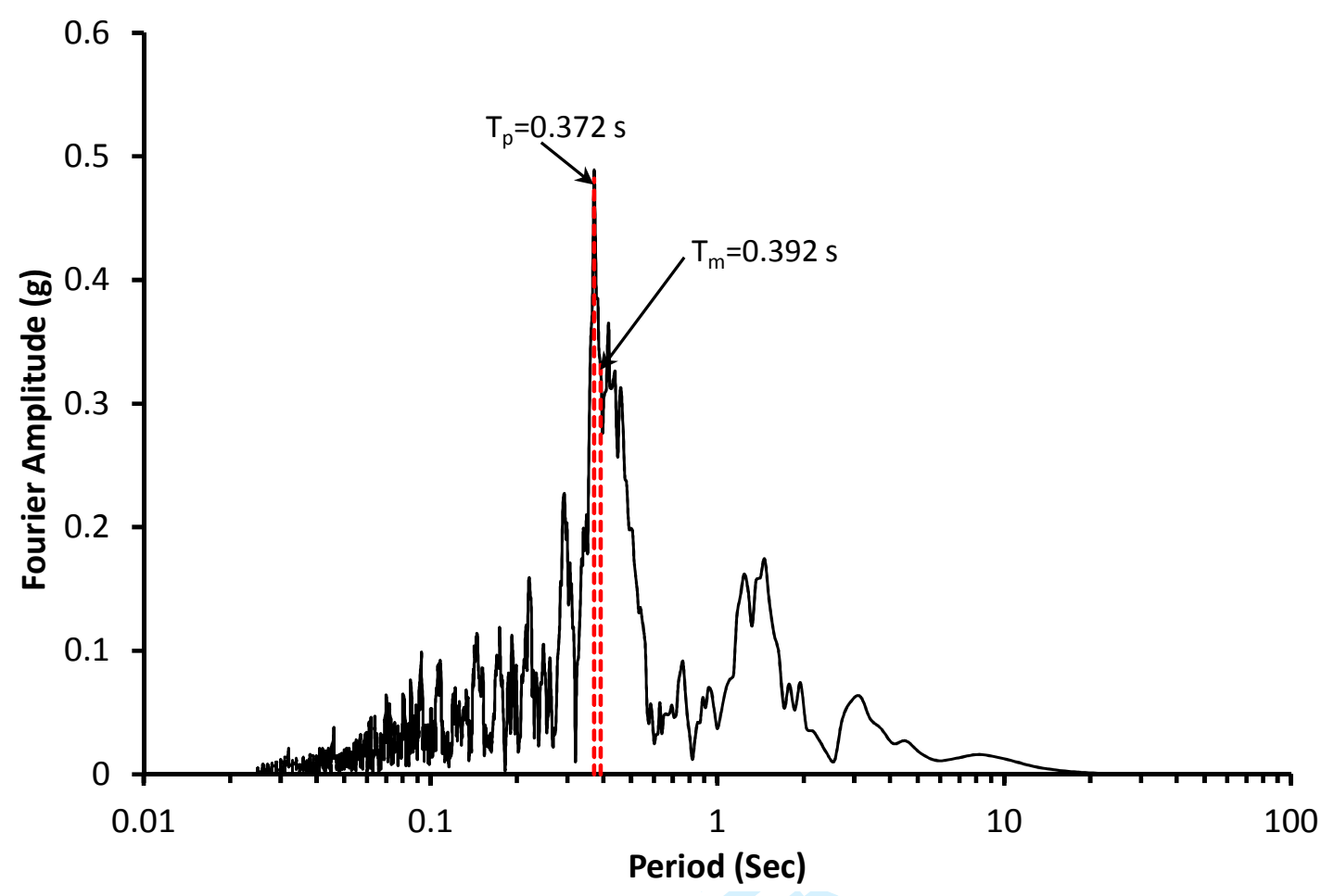

Figure 5: Fourier amplitude transform of the Loma Prieta earthquake record 


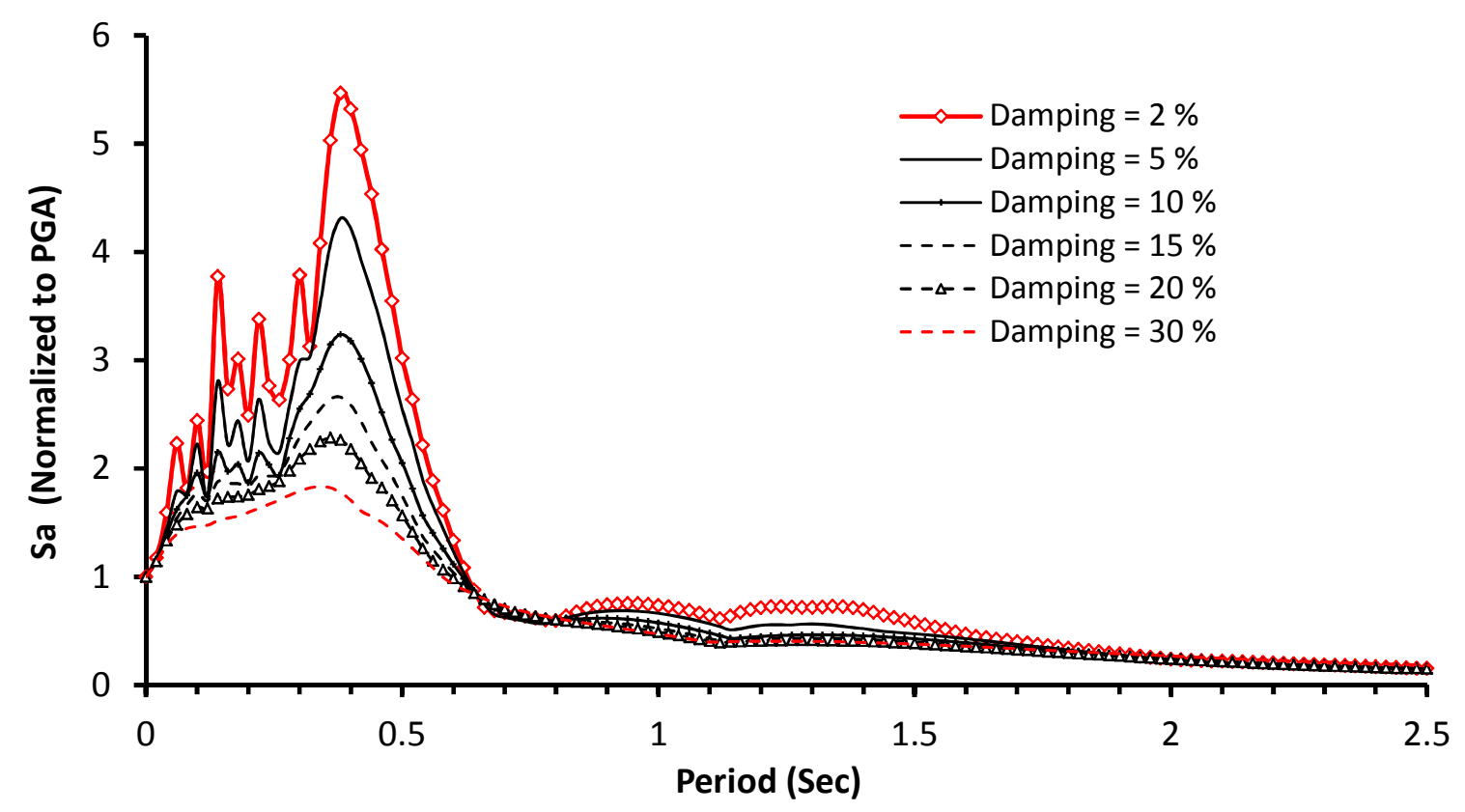

Figure 6: Response spectra of the Loma Prieta earthquake for different damping ratios 


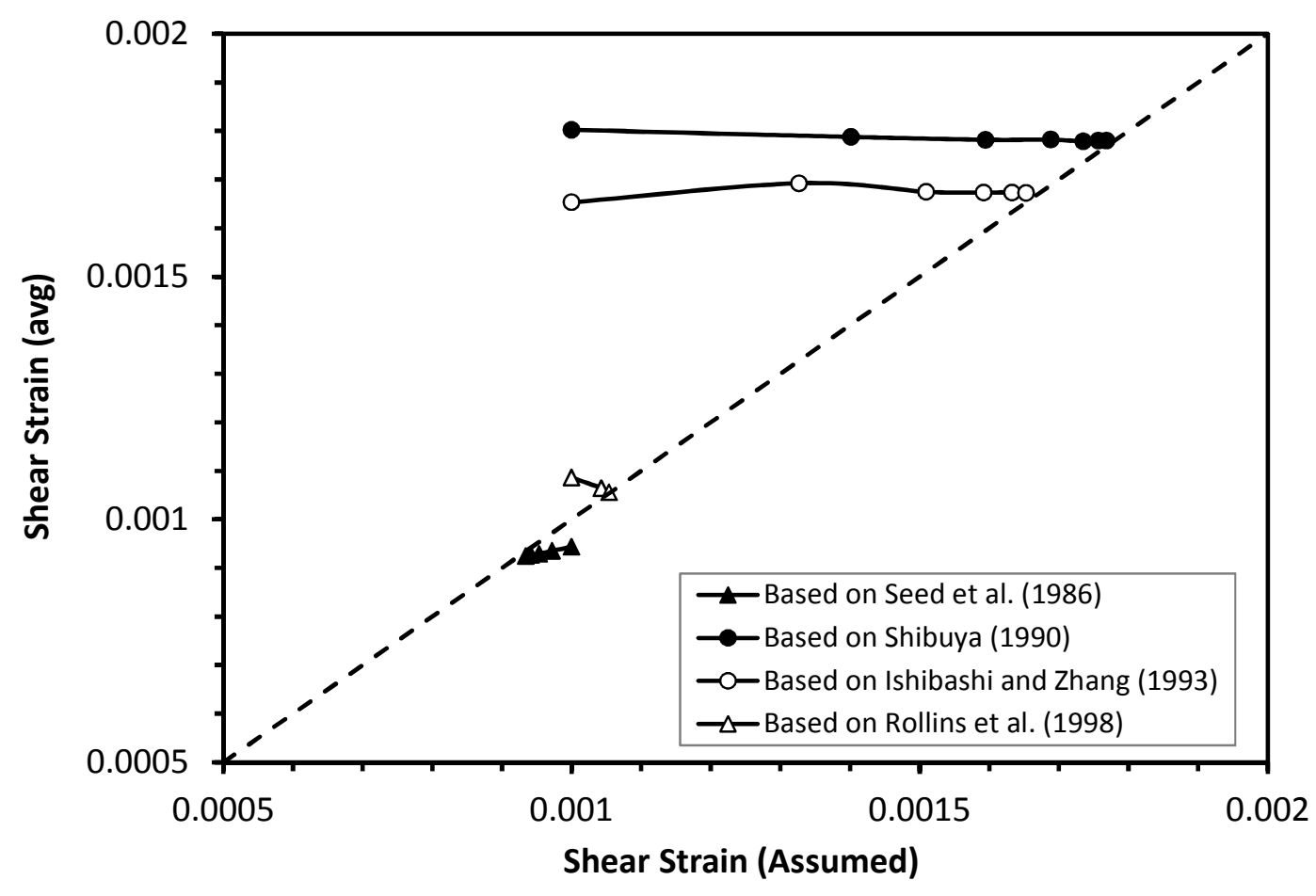

Figure 7: Iterative procedure of equivalent linear approach using four stress-strain dependencies 


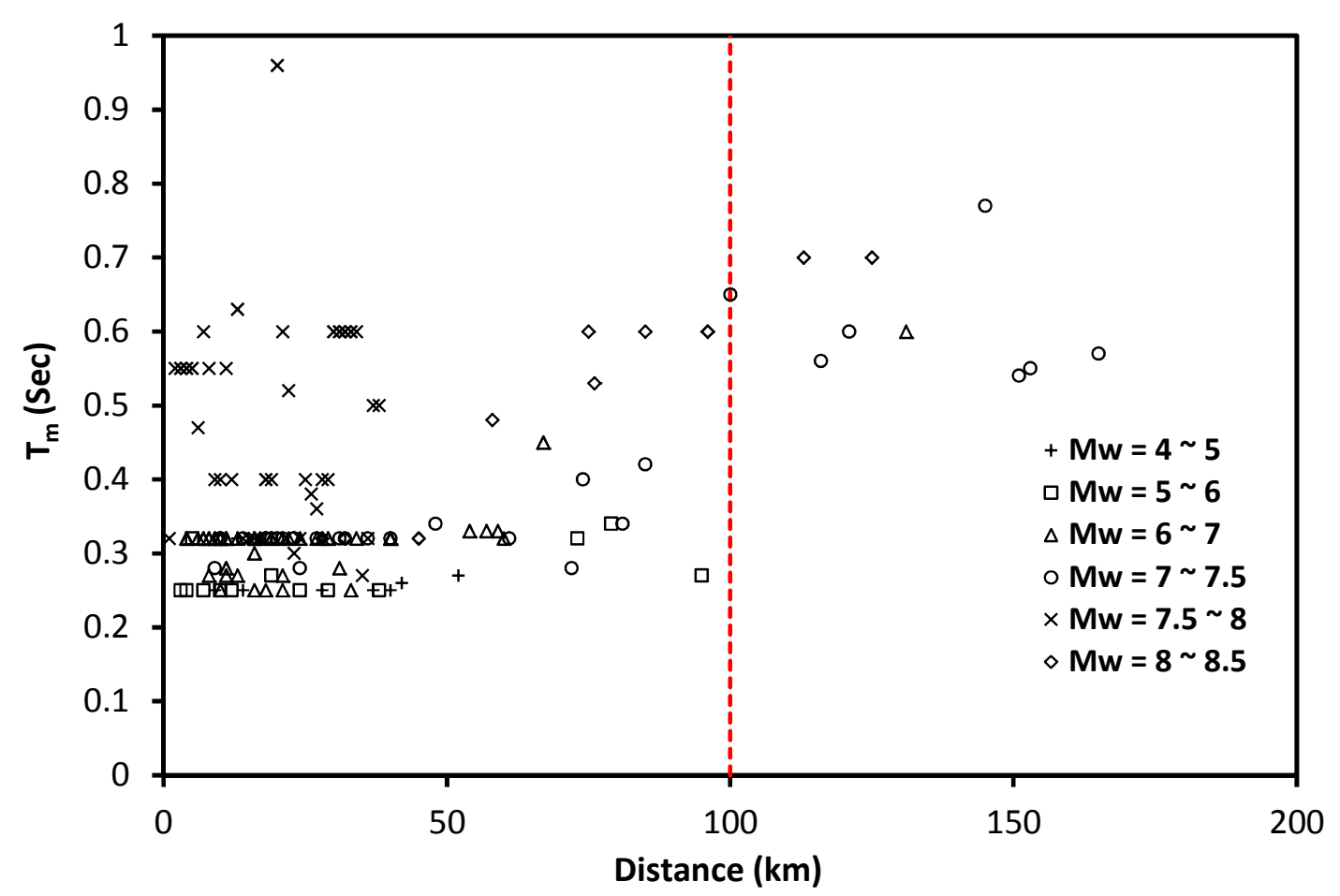

Figure 8: Variation of the predominant period of earthquakes vs. distance (data from Singh and Roy 2009) 


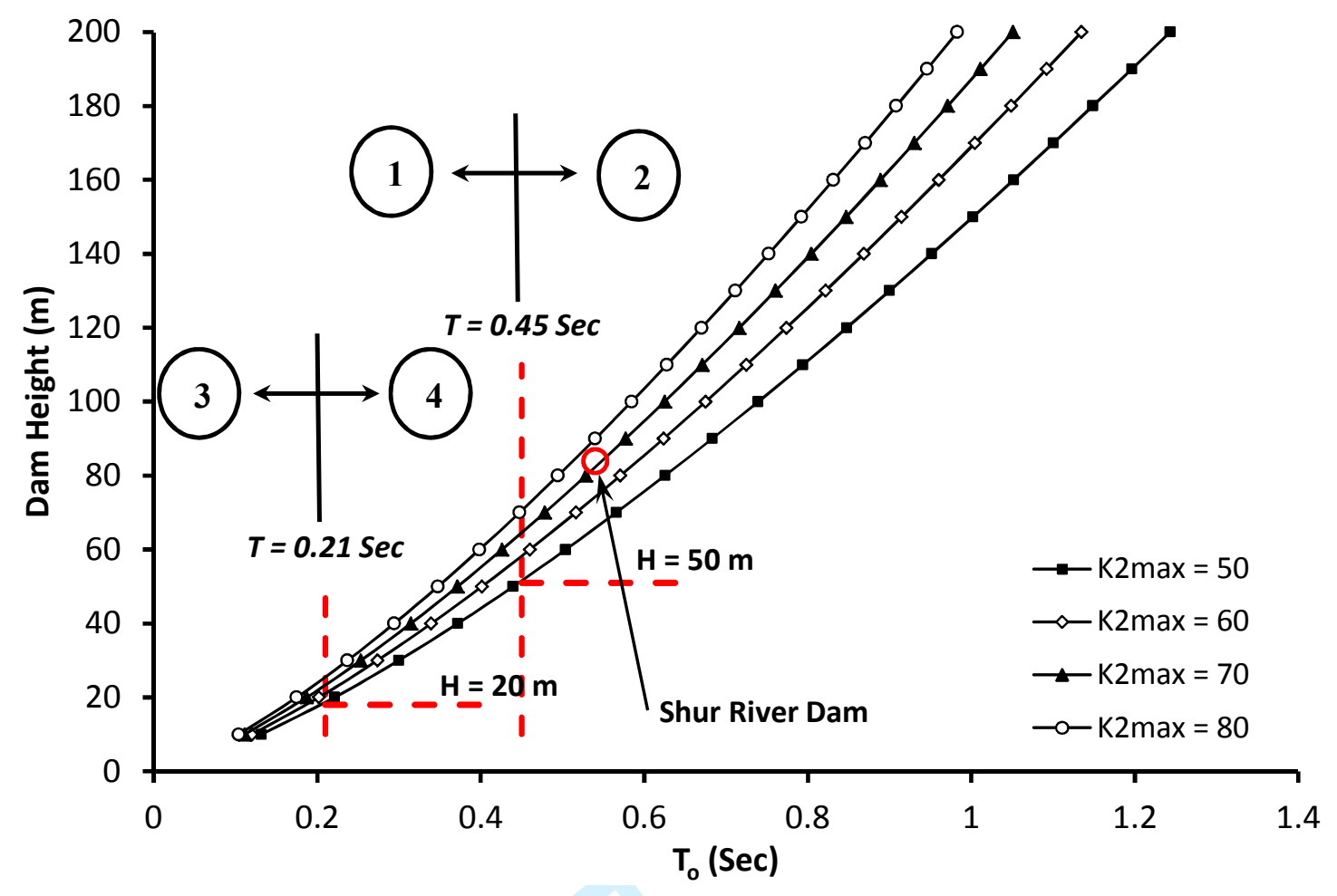

Figure 9: Variation of fundamental period with height for earthfill dams 


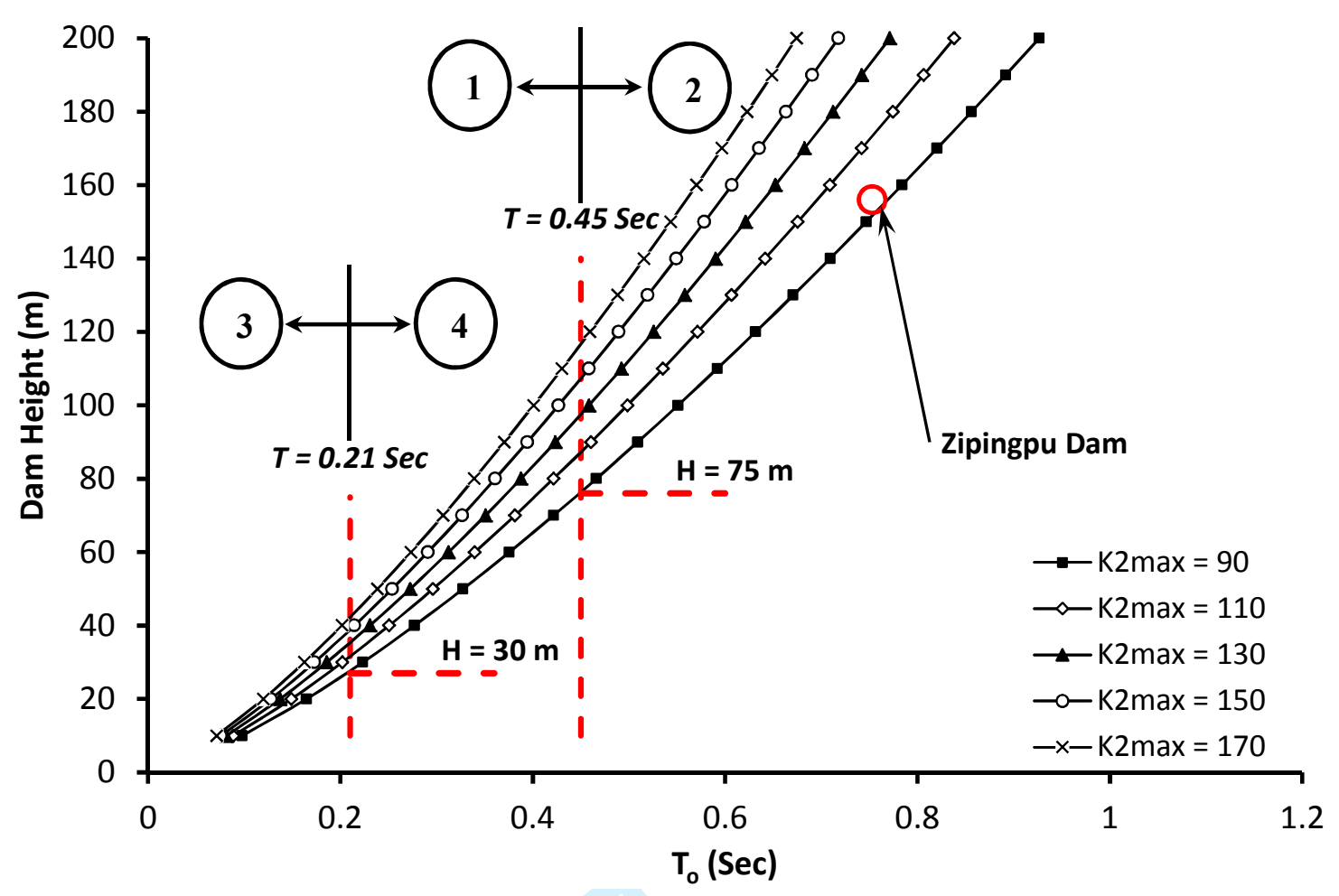

Figure 10: Variation of fundamental period with height for rockfill dams 


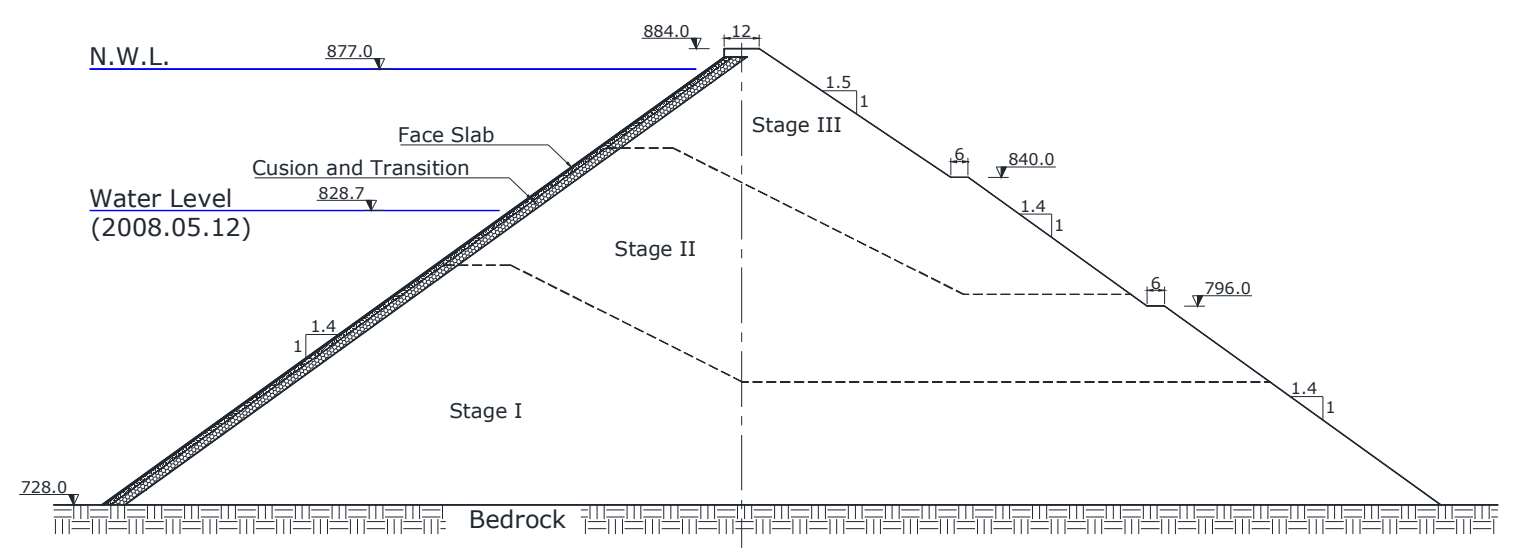

Figure 11: Typical cross section of Zipingpu dam (cross section 0+251, all units in Meters) 


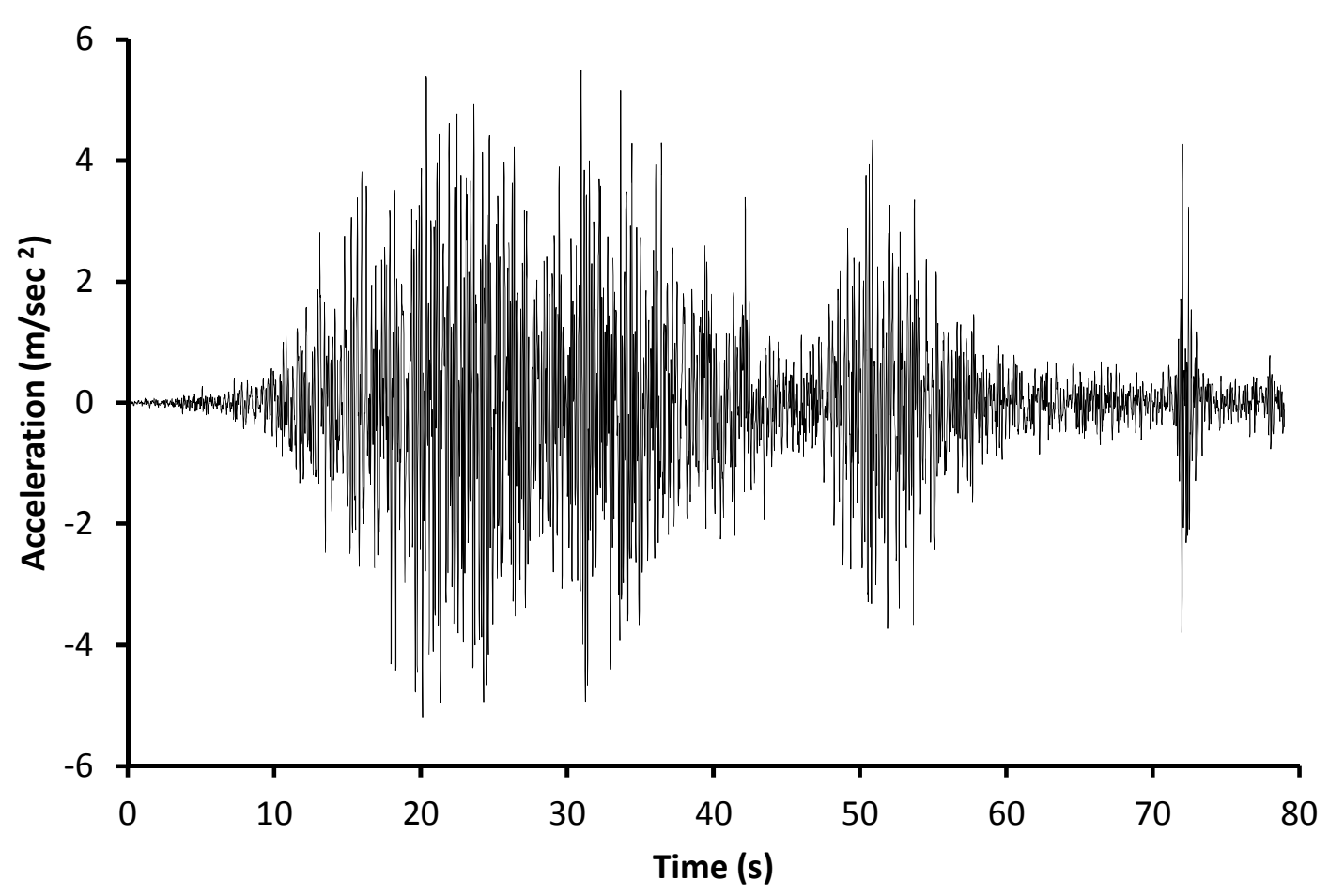

Figure 12: Acceleration time history of the E-W component of the "5.12" earthquake as recorded in Mao Town and scaled to $0.55 \mathrm{~g}$ 


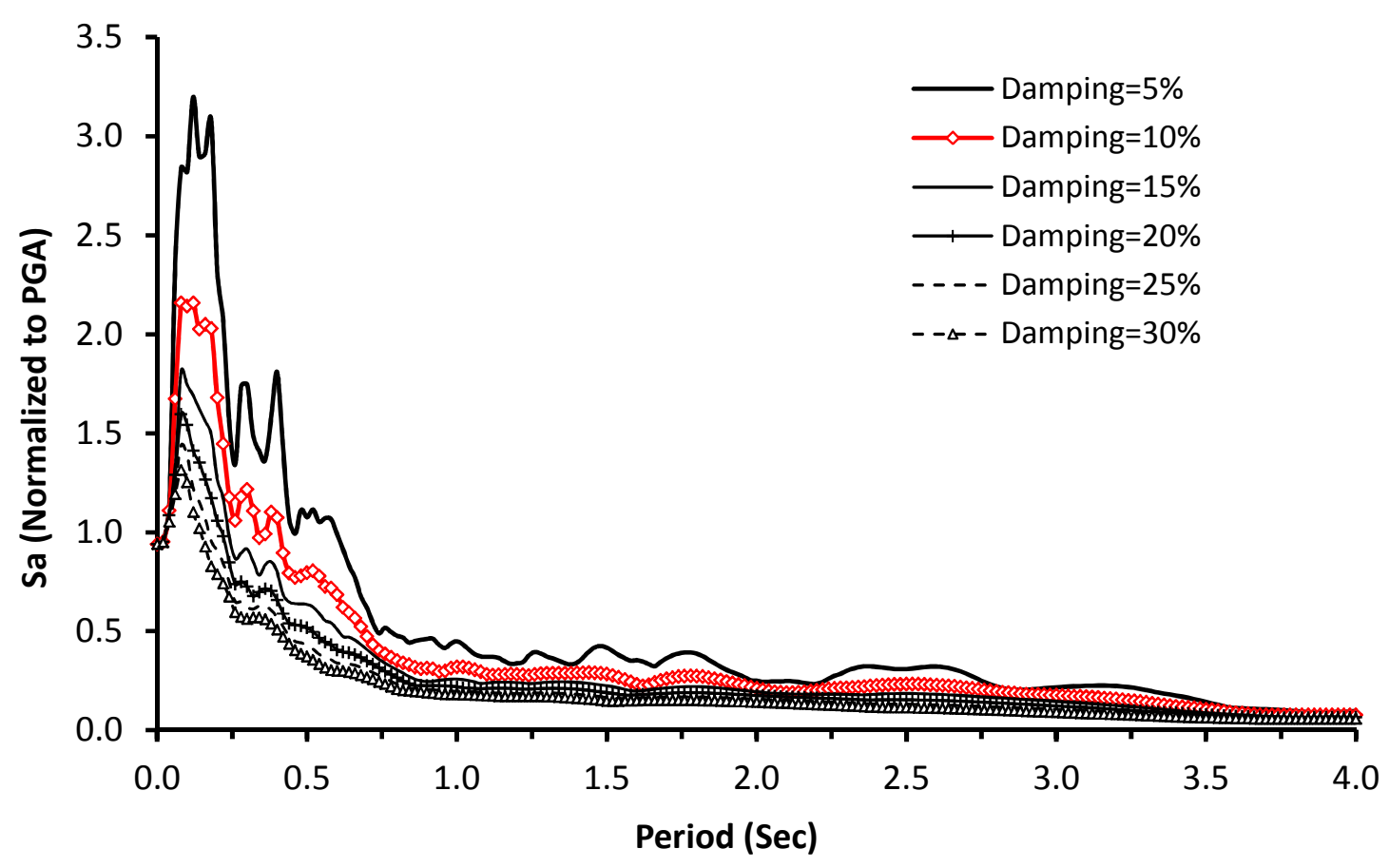

Figure 13: Response spectra of the "5.12" earthquake (Mao Town record) 


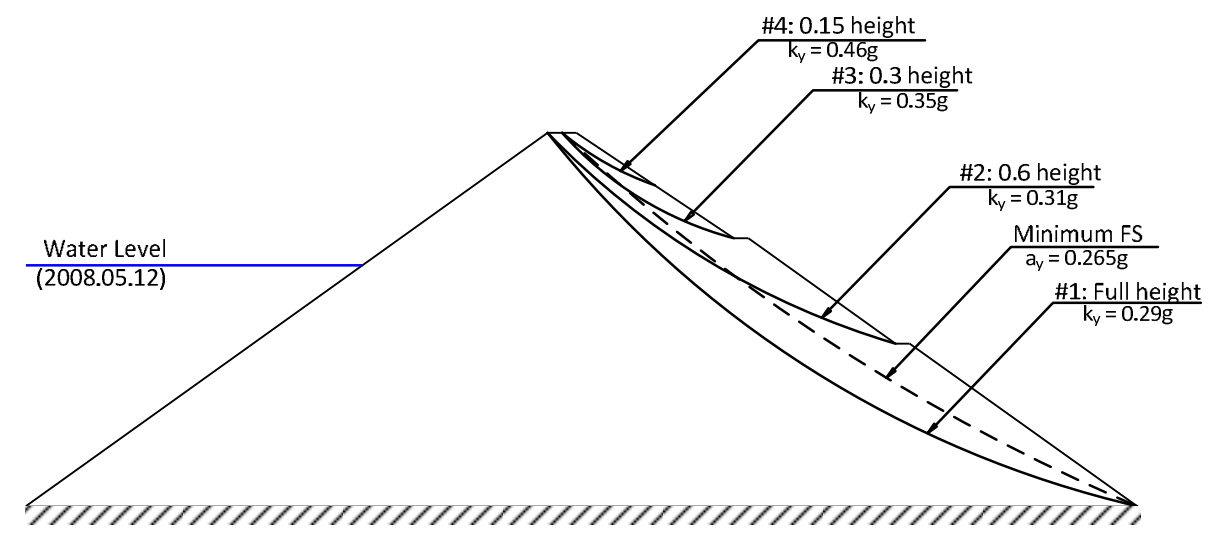

(a)

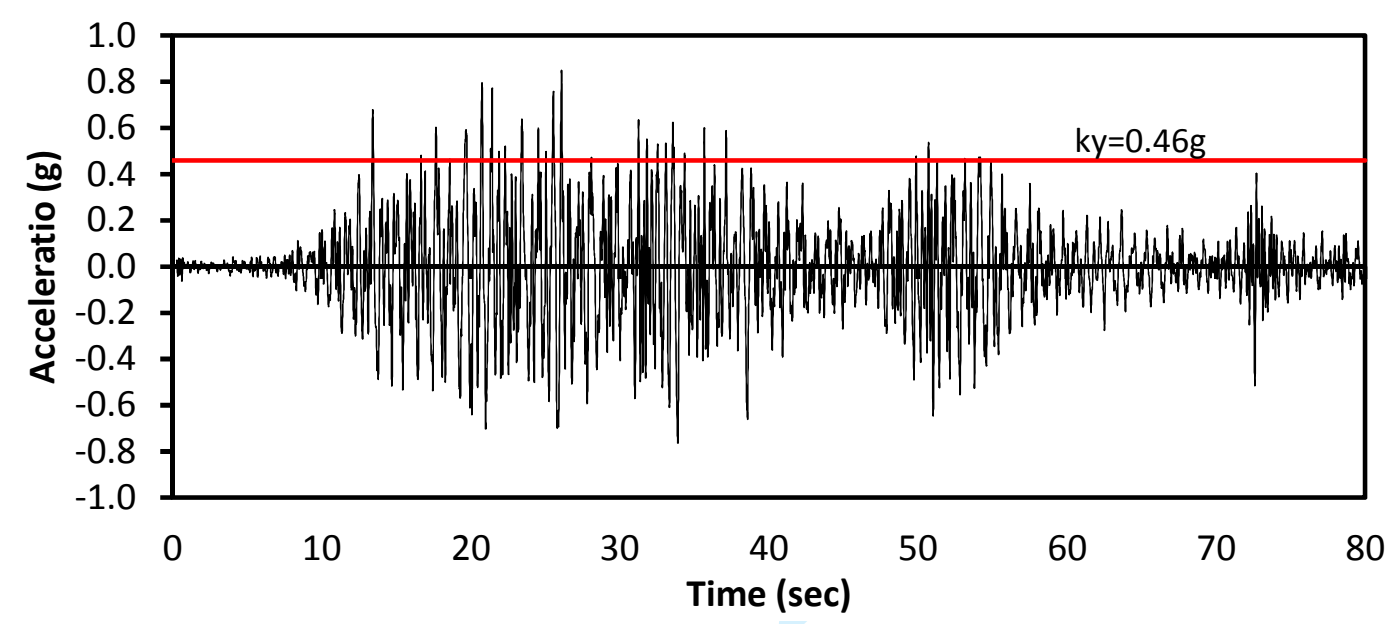

(b)

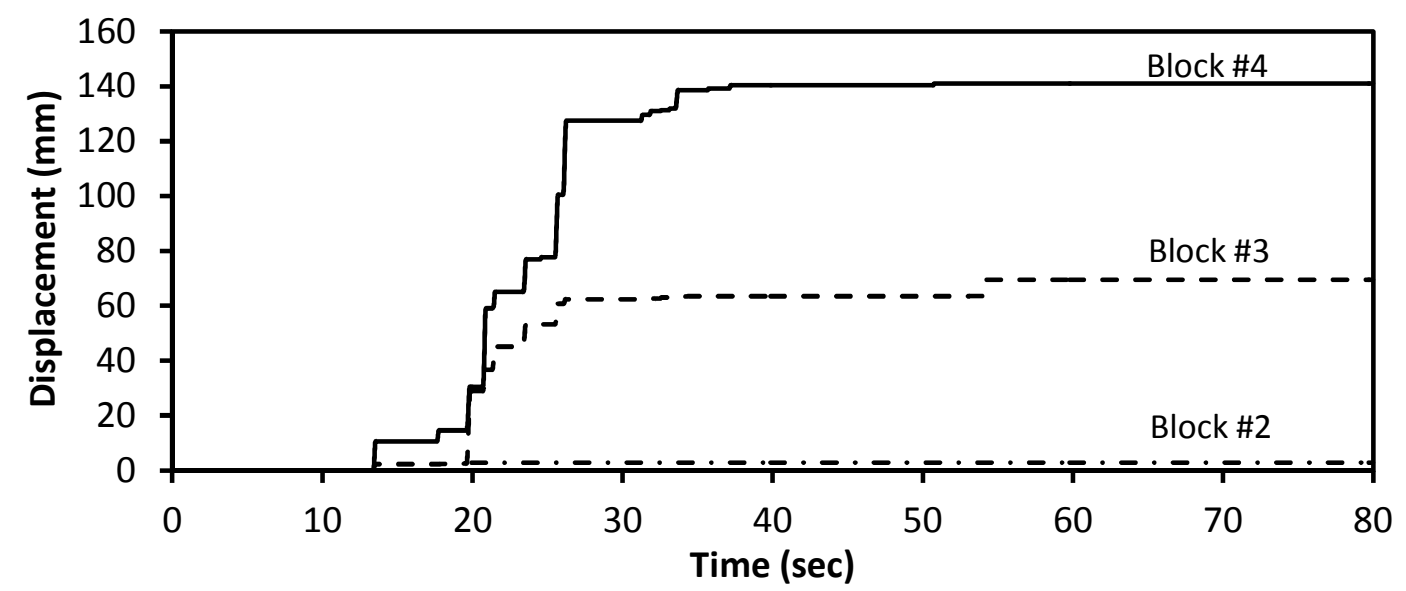

(c)

Figure 14: Simplified seismic analysis of Zipingpu dam, (a) location of the four sliding blocks, (b) acceleration time history for block \#4, and (c) displacement time history for blocks \#2, \#3, \#4 


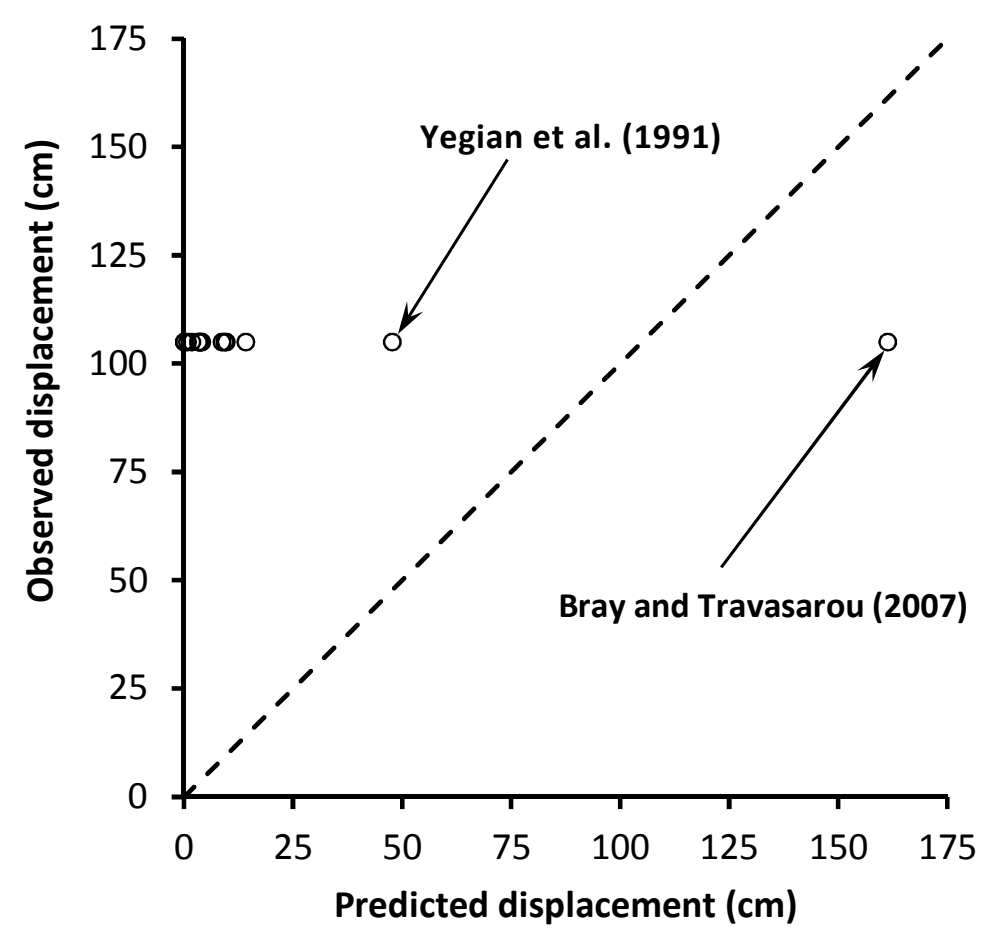

Figure 15: Observed vs. predicted displacements of Zipingpu dam obtained from simplified models 